UNIVERSIDADE DE SÃO PAULO

FACULDADE DE ECONOMIA, ADMINISTRAÇÃO E CONTABILIDADE DEPARTAMENTO DE ECONOMIA PROGRAMA DE PÓS-GRADUAÇÃO EM ECONOMIA

\title{
Rendas do petróleo e desenvolvimento local no Brasil: um estudo empírico com base no produto municipal
}

Robison Francisco Kudamatsu

Orientador: Prof. Dr. Fernando Antonio Slaibe Postali

SÃo PAULO 
Prof. Dr. Marco Antônio Zago

Reitor da Universidade de São Paulo

Prof. Dr. Adalberto Américo Fischmann

Diretor da Faculdade de Economia, Administração e Contabilidade

Prof. Dr. Eduardo Amaral Haddad

Chefe do Departamento de Economia

Prof. Dr. Ariaster Baumgratz Chimeli

Coordenador do Programa de Pós-Graduação em Economia 


\title{
Rendas do petróleo e desenvolvimento local no Brasil: um estudo empírico com base no produto municipal
}

\author{
Dissertação apresentada ao Programa de \\ Pós-Graduação em Economia do \\ Departamento de Economia da Faculdade \\ de Economia, Administração e \\ Contabilidade da Universidade de São \\ Paulo como requisito parcial para a \\ obtenção do título de Mestre em Ciências.
}

Orientador: Prof. Dr. Fernando Antonio Slaibe Postali

Versão Original

SÃO PAULO 
FICHA CATALOGRÁFICA

Elaborada pela Seção de Processamento Técnico do SBD/FEA/USP

Kudamatsu, Robison Francisco

Rendas do petróleo e desenvolvimento local no Brasil: um estudo empírico com base no produto municipal / Robison Francisco Kudamatsu. - São Paulo, 2017.

$45 \mathrm{p}$.

Dissertação (Mestrado) - Universidade de São Paulo, 2017.

Orientador: Fernando Antonio Slaibe Postali.

1. Desenvolvimento econômico 2. Produto interno bruto 3. Royalties 4. Petróleo I. Universidade de São Paulo. Faculdade de Economia, Administração e Contabilidade. II. Título.

CDD - 338.9 


\section{AGRADECIMENTOS}

Dedico esta dissertação de mestrado a minha família, principalmente aos meus pais, Elci e Paulino, ao meu irmão, Breno, e a minha avó Lavínia. Sou eternamente grato a vocês pelo apoio, pelos valores transmitidos, pela formação e por propiarem as melhores condições para que eu pudesse desenvolver as minhas potencialidades.

Ao professor Fernando Postali, gostaria de dizer que me sinto um privilegiado por ter sido seu orientando na graduação e agora no mestrado. Além de ser um professor exemplar, dedicado e preocupado com os seus alunos, é um excelente orientador, atencioso, que fornece valiosos conselhos. Muito obrigado!

Com relação ao corpo docente do Instituto de Pesquisas Econômicas da Universidade de São Paulo (IPE/USP), agradeço, em especial, as professoras Dolores e Fabiana por suas observações e sugestões durante o processo de qualificação e de avaliação de progresso deste trabalho. Também agradeço aos demais professores (David, Alan, Chiappin, Nakane, Mauro, Rafael, Nakaguma, Bruno, De Losso, Vera, Paula e Kanczuk), com os quais eu tive a oportunidade de ser aluno, pelo empenho e dedicação ao nosso programa de pós-graduação.

Aos meus colegas de classe, ingressantes de 2015, quero dizer que foi uma enorme satisfação e alegria ter compartilhado os últimos anos com vocês. Em particular, a amizade e convivência com Renan, Arthur, Thiago e Juliana foram muito importantes para mim nesse período.

Por fim, agradeço ao Conselho Nacional de Desenvolvimento Científico e Tecnológico (CNPq) pelo auxílio financeiro durante o mestrado. 


\section{RESUMO}

Esta dissertação tem como objetivo analisar o impacto das transferências de royalties de petróleo no crescimento do PIB dos municípios beneficiados no Brasil. Para tanto, é utilizado o método Duplamente Robusto em um painel de municípios observados entre 2004 e 2013. Essa metodologia consiste em duas etapas: primeiramente, estima-se a probabilidade condicional dos municípios receberem as rendas do petróleo, ou seja, o propensity score; em seguida, estima-se um modelo em painel de efeitos fixos ponderado pela estimativa anterior. A principal vantagem desse procedimento é a obtenção de estimadores consistentes quando ao menos uma dessas etapas é especificada corretamente. Os resultados obtidos vão na direção contrária à tese de Maldição dos Recursos Naturais proveniente de rendas de petróleo e derivados. No caso, as evidências apontam que os royalties não afetam a taxa de crescimento do produto per capita municipal, apesar de promoverem um aumento geral nas despesas orçamentárias locais. 


\begin{abstract}
This Master Thesis in Economics aims to analyze the impact of oil revenue transfers on the economic growth of benefited municipalities in Brazil. For this purpose, the Doubly Robust is the method applied to a panel of localities observed between 2004 and 2013. This methodology consists of two stages. Firstly, it estimates the conditional likelihood of receiving the oil royalties, i.e., the propensity score. Then it estimates a fixed effect model weighted by the previous estimative. The main advantage of this procedure is to obtain consistent estimators when at least one of the mentioned stages is correctly specified. The results refute the Natural Resources Curse hypothesis in the Brazilian oil revenues. More specifically, the evidence is that royalties do not affect the municipal GDP per capita growth, despite providing a general increase in local expenses.
\end{abstract}




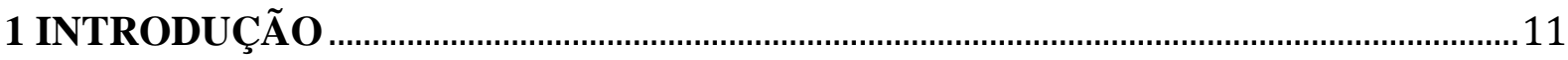

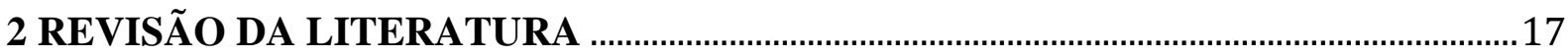

3 METODOLOGIA

4 BASE DE DADOS

5 RESULTADOS

6 ROYALTIES, GASTO PÚBLICO E DESENVOLVIMENTO ……………………..............37

7 CONSIDERAÇÕES FINAIS …………………………………...............................................

REFERÊNCIAS BIBLIOGRÁFICAS......................................................................................

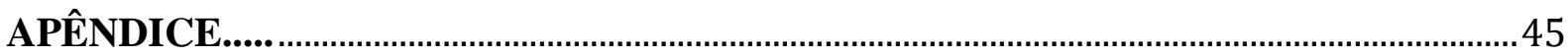




\section{LISTA DE ILUSTRAÇÕES}

Figura 1 - Preços Spot de Petróleo Bruto......................................................................................12

Figura 2 - Royalties e Participações Especiais no Brasil ..............................................................12

Figura 3 - Divisão dos Royalties entre UF no Brasil (\% do Total) ...............................................14

Figura 4 - Histograma de Propensity Score dos Municípios..........................................................30

Figura 5 - Histograma de Propensity Score no Suporte Comum ...................................................31 


\section{LISTA DE TABELAS}

Tabela 1 - Parcela dos Royalties do Petróleo na Receita Orçamentária Municipal

Tabela 2 - Estatísticas Descritivas - Municípios Receptores de Royalties do Petróleo (em valores reais, per capita) 25

Tabela 3 - Composição do IFDM. 25

Tabela 4 - Estatísticas Descritivas - Municípios Brasileiros Tratados

Tabela 5 - Estatísticas Descritivas - Municípios Brasileiros Não Tratados 28

Tabela 6 - Probabilidade Condicional de Tratamento - Modelo LOGIT 29

Tabela 7 - Balanceamento das Variáveis - Teste da Diferença de Médias 32

Tabela 8 - Estimação com Variáveis Contemporâneas. 34

Tabela 9 - Estimação com Variáveis Defasadas 34

Tabela 10 - Estimação com Variáveis Defasadas e Contemporâneas 35

Tabela 11 - Estimação com Variáveis Defasadas e Contemporâneas Selecionadas I .36

Tabela 12 - Estimação com o PIB Ex-Indústria como Variável Dependente 37

Tabela 13 - Royalties do Petróleo e Orçamento Municipal 40

Tabela 14 - Estimação com Variáveis Defasadas e Contemporâneas Selecionadas II 45 


\section{INTRODUÇÃO}

Não bastasse sua vasta extensão territorial, o Brasil também é beneficiado pela abundância em recursos naturais renováveis, como água, e não-renováveis, a exemplo de minério de ferro e o petróleo. No caso específico do petróleo - objeto de análise neste trabalho - além das benesses provenientes de sua produção, comercialização e utilização, os munícipios afetados por sua extração recebem compensações financeiras, conhecidas por royalties do petróleo ${ }^{1}$.

No Brasil, o marco regulatório para petróleo e derivados foi estabelecido com a lei n 9.478 - a Lei do Petróleo - em agosto de 1997, a qual quebrou o monopólio estatal da Petrobras na exploração desses produtos. Além disso, houve um aumento expressivo das alíquotas (de $5 \%$ para $10 \%$ do valor da produção) e uma mudança no cálculo dos royalties petrolíferos, que passou a depender do preço internacional do produto. Com base na Figura 1, nota-se que, puxado pela forte demanda por commodities em mercados emergentes, o preço do barril de petróleo cresceu gradativamente até atingir seu ápice na metade de 2008 em meio à eclosão da Crise Financeira Internacional; no período subsequente, houve retomada e estabilização dos preços em torno de US $\$ 100$ por barril até a metade de 2014, quando a desaceleração da China e o crescimento da oferta de petróleo dos EUA (a partir de óleo de xisto), que se tornou o maior produtor, deprimiram sua demanda.

Dessa maneira, o volume de royalties do petróleo - royalties propriamente ditos e participações especiais (forma de compensação diferenciada, proporcional à produção e à rentabilidade de determinados campos de petróleo $)^{2}$ - pagos pelo Tesouro Nacional às regiões impactadas pela produção de petróleo cresceu de modo significativo até 2014, conforme ilustrado na Figura 2. É importante ressaltar que o principal critério para o seu recebimento é geográfico, sendo a maior parcela destinada às municipalidades produtoras seguida por aquelas afetadas indiretamente por sua produção ${ }^{3}$. Em contrapartida, a legislação vigente não estabelece critérios muito restritivos para aplicação desses recursos, sendo vedado apenas o

\footnotetext{
${ }^{1}$ Paralelamente a isso, caso lhes sejam devidos, os municípios podem receber compensação financeira pela utilização de recursos hídricos e royalties pagos pela usina de Itaipu Binacional - ambos decorrentes da exploração comercial de água no território local - e a Compensação Financeira pela Exploração de Recursos Minerais (CFEM) por atividades na mineração.

2 Nesta dissertação, o termo "royalties do petróleo" corresponde à totalidade das receitas provenientes desse recurso, ou seja, equivale à soma de royalties propriamente ditos e participações especiais. Estas últimas são compensações extraordinárias incidentes sobre projetos de alta lucratividade.

${ }^{3}$ Além do critério geográfico, o volume transferido depende do tamanho da população local e da localização de instalações relacionadas ao transporte e à produção de petróleo e derivados.
} 
seu uso no pagamento de dívidas ${ }^{4}$ e em despesas com folha de pagamento ${ }^{5}$. A fiscalização acerca da conformidade com as regras de alocação é responsabilidade do Tribunal de Contas Estadual de cada Unidade Federativa (UF).

Figura 1 - Preços Spot de Petróleo Bruto

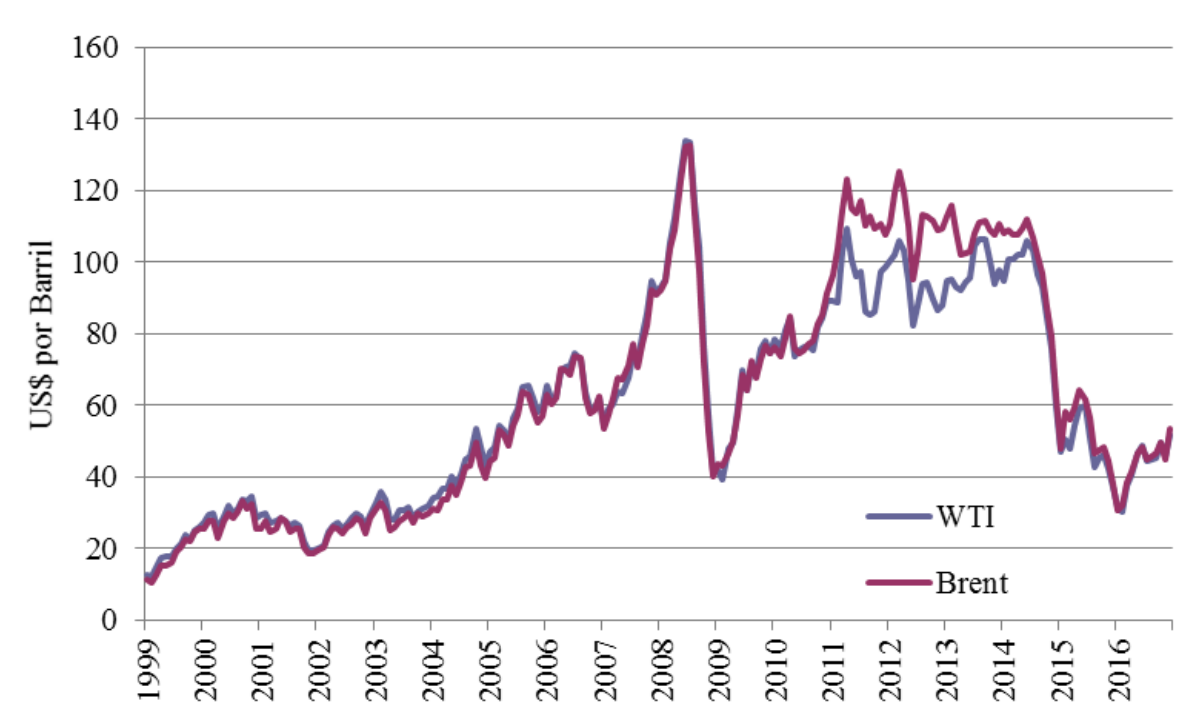

Fonte: U.S. Energy Information Administration. Elaboração Própria.

Figura 2 - Royalties e Participações Especiais no Brasil

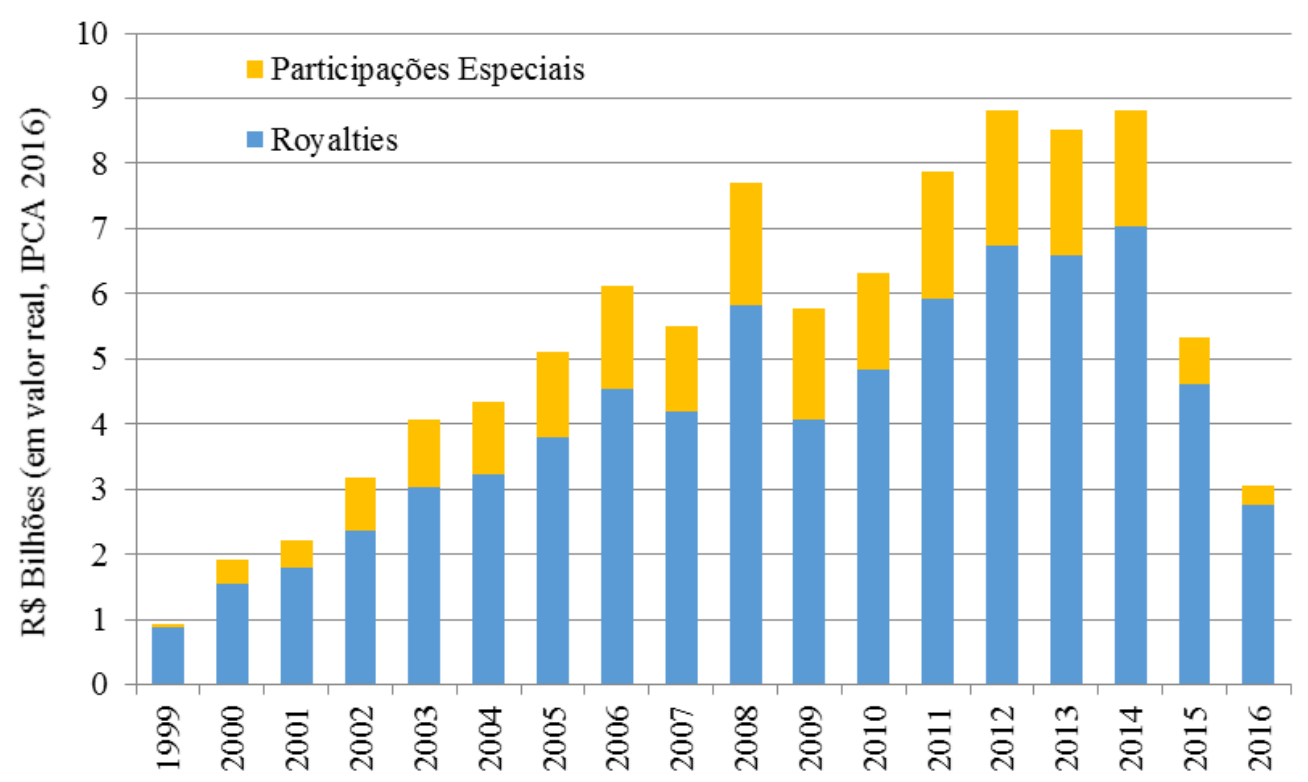

Fonte: ANP. Elaboração Própria.

\footnotetext{
${ }^{4}$ Exceto quitação de débitos com o governo federal.

${ }^{5}$ A lei $n^{\text {o }} 12.858$, de setembro de 2013, autoriza o custeio de despesas com manutenção e desenvolvimento do ensino, inclusive as relativas ao pagamento de salários aos professores em efetivo exercício na rede pública.
} 
No período pós-Crise, vale destacar uma outra mudança institucional relevante no setor de minas e energia - o marco regulatório do pré-sal. Até então, as atividades de exploração e produção de petróleo eram regidas exclusivamente pelo sistema de concessão ${ }^{6}$. No entanto, com a promulgação das leis nº 12.276 e 12.351/2010, estabelecendo o sistema de cessão onerosa e de partilha de produção ${ }^{7}$ respectivamente, os três modelos passaram a coexistir. Adicionalmente, a lei 12.351 criou o Fundo Social, por meio do qual, os proventos dos contratos de partilha seriam recebidos visando ao financiamento de programas de combate à pobreza e ao desenvolvimento da educação, cultura, ciência e sustentabilidade ambiental. Com isso, em meio ao cenário de preços internacionais elevados e de prognósticos otimistas sobre as reservas do pré-sal em termos de volume e rentabilidade, a União buscou assegurar tanto uma parcela maior das divisas, quanto um maior controle sobre a atividade petrolífera.

Por outro lado, a análise dos dados da Agência Nacional do Petróleo (ANP) mostra que a distribuição dos royalties é fortemente concentrada em poucas UF. Em 2016, por exemplo, apenas RJ, BA, RN, ES e SP concentraram quase $98 \%$ das transferências totais de royalties, sendo que o Estado do Rio de Janeiro recebeu 62\% do montante total (ver Figura 3). Essa situação díspar levou o Congresso Nacional a discutir uma mudança na regra de distribuição dos royalties, que culminou na lei $n^{\circ} 12.734 / 2012$. Assim, propôs-se a criação de fundos especiais destinados a transferir parte das receitas da totalidade de contratos (tanto os novos quando os em andamento) de concessão e partilha para todos os estados e munícipios, com base na regra de rateio utilizada no Fundo de Participação dos Estados (FPE) e Fundo de Participação dos Municípios (FPM). Além disso, em contraposição à regra anteriormente mencionada, foram estabelecidos limites mais restritos para o destino dessas rendas ao elencar os investimentos permitidos. Contudo, as principais UF beneficiadas pela legislação anterior, cientes da iminência de queda em suas receitas de royalties, entraram com ações no Supremo Tribunal Federal (STF) contra a nova lei. Em 2013, foi concedida uma liminar para suspender a validade dessa nova distribuição proposta. Atualmente, o processo sobre a divisão dos royalties do petróleo encontra-se à espera de julgamento no STF.

\footnotetext{
${ }^{6}$ Em síntese, o concessionário adquire o campo através de um processo de licitação, assumindo todos os riscos do empreendimento.

${ }^{7} \mathrm{Na}$ cessão onerosa, a União cede à Petrobras a exclusividade de determinado campo. Na partilha de produção, a Petrobras tem uma participação mínima de $30 \%$ e o restante é licitado. Em ambos sistemas, os riscos são dos concessionários.
} 
Figura 3 - Divisão dos Royalties entre UF no Brasil (\% do Total)

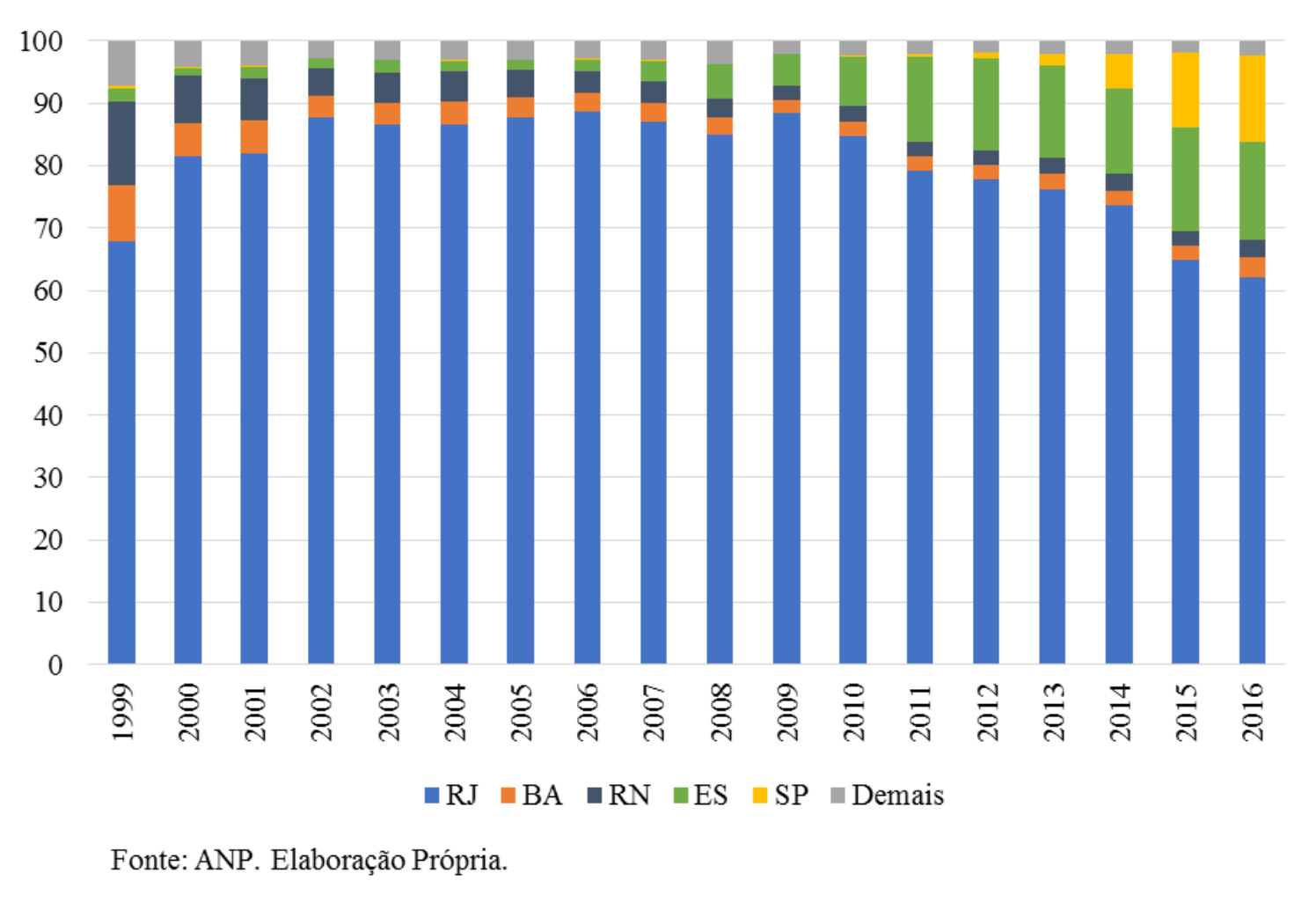

A crescente importância dos royalties do petróleo também incentivou novas pesquisas acadêmicas, as quais relacionam o seu recebimento com a situação fiscal, social e econômica das localidades beneficiadas e é nesse contexto que esta pesquisa se situa. Esta dissertação se utiliza do método Duplamente Robusto para avaliar o impacto das rendas do petróleo sobre o desenvolvimento local dos municípios beneficiados no Brasil, medido pela evolução da taxa de crescimento do Produto Interno Bruto (PIB) per capita ${ }^{8}$. A hipótese a ser investigada é se a produção de petróleo e o consequente fluxo de recursos transferidos às municipalidades estimularam a economia local, elevando o seu produto per capita. Trata-se de um resultado desejável à luz dos princípios teóricos de aplicação das rendas de recursos exauríveis, que visam garantir o benefício intertemporal para as gerações atual e subsequentes no país (Hartwick, 1977).

Este trabalho se justifica tanto pela relevância do tema, quanto pela estratégia de identificação econométrica a ser empregada na análise da relação entre os royalties do petróleo e o desenvolvimento econômico dos municípios beneficiados.

\footnotetext{
${ }^{8}$ A utilização do PIB per capita municipal como métrica de desenvolvimento econômico pode ser justificada através de correlações elevadas entre essa variável e indicadores de desenvolvimento humano - redução na taxa de mortalidade infantil, aumento da expectativa de vida e avanços na escolaridade. Para mais informações sobre esse assunto, ver Raj (1998).
} 
Conforme exposto anteriormente, a possível alteração na lei que regulamenta as transferências de royalties pode modificar substancialmente o contingente de localidades favorecidas, bem como reduzir o volume de recursos transferidos aos atuais beneficiários. Além dessa incerteza jurídica e do contexto de recuperação econômica do Brasil, a estabilização dos preços do petróleo em patamar 50\% inferior ao do começo da década (vide Figura 1) configura um cenário desafiador para toda a cadeia receptora de rendas petrolíferas. Existe não somente uma notória dependência de royalties nas receitas dos municípios, mas também um manejo inadequado desses recursos ${ }^{9}$. A Tabela 1 aborda a questão da dependência a partir do cálculo de sua parcela na receita orçamentária municipal; embora não seja possível inferir o aumento da dependência ao longo do tempo, observa-se que parcela de municípios que mais recebem royalties do petróleo (acima do $90^{\circ}$ percentil) possuem, em média (no período analisado), cerca de $20 \%$ de suas rendas provenientes desse recurso, o que é temerário dada a volatilidade desses recursos. Ademais, o contexto pós-crise internacional, com a introdução do marco regulatório do pré-sal e a divulgação de dados no período (e.g.: Censo 2010), representa um convite à pesquisa visando compreender os impactos locais dos royalties. Diante desse cenário, a sua compreensão se torna preponderante para que tomem decisões fundamentadas ao desenharem um arranjo de divisão e, sobretudo, de manejo de royalties que efetivamente beneficie a sociedade.

Do ponto de vista metodológico, a dissertação busca contribuir com estratégias de identificação mais acuradas para investigar os impactos das rendas petroleiras nas realidades dos municípios contemplados. A abordagem econométrica do Duplo Robusto representa um aprimoramento metodológico em relação aos estudos até agora realizados, mais especificamente, visa contornar as limitações encontradas em Postali (2009), lidando com o problema de viés de variável omitida (uma ameaça à identificação causal dos efeitos dos royalties sobre o PIB) ao aprimorar a comparabilidade entre os grupos de controle e tratamento.

Em geral, a literatura sobre Maldição dos Recursos Naturais (MRN) no Brasil, especialmente a relacionada ao petróleo, aponta que as receitas desses recursos geram um menor crescimento econômico nas regiões beneficiadas (Postali, 2009), que sua produção reduz o PIB não industrial municipal (Monteiro e Ferraz, 2010), além de pouco afetar a provisão de serviços públicos locais (Monteiro e Ferraz, 2010; Postali e Nishijima, 2011 e

\footnotetext{
${ }^{9}$ Para exemplificar, tem sido amplamente divulgada a crise orçamentária e social do RJ causada, entre outros fatores, pela redução dos royalties, bem como exposto o manejo inadequado desses recursos em algumas localidades, consubstanciado nos gastos com obras públicas, custeio e publicidade.
} 
2013; Caselli e Michaels, 2013). Portanto, os trabalhos realizados até agora trazem evidências de que o país pode estar sob os efeitos da MRN nas rendas petrolíferas.

Tabela 1 - Parcela dos Royalties do Petróleo na Receita Orçamentária Municipal

\begin{tabular}{|c|c|c|c|c|c|c|c|c|}
\hline \multirow{2}{*}{$\begin{array}{l}\text { Percentil } \\
\text { Ano }\end{array}$} & \multicolumn{2}{|c|}{$0-100 \%$} & \multicolumn{2}{|c|}{$>50 \%$} & \multicolumn{2}{|c|}{$>75 \%$} & \multicolumn{2}{|c|}{$>90 \%$} \\
\hline & \# Obs & Média & \# Obs & Média & \# Obs & Média & \# Obs & Média \\
\hline 2000 & 703 & $\begin{array}{c}2.7 \% \\
(0.078)\end{array}$ & 280 & $\begin{array}{c}6.7 \% \\
(0.112)\end{array}$ & 130 & $\begin{array}{l}13.7 \% \\
(0.134)\end{array}$ & 31 & $\begin{array}{l}26.9 \% \\
(0.198)\end{array}$ \\
\hline 2001 & 761 & $\begin{array}{l}2.6 \% \\
(0.07)\end{array}$ & 276 & $\begin{array}{c}7.0 \% \\
(0.103)\end{array}$ & 136 & $\begin{array}{l}13.5 \% \\
(0.114)\end{array}$ & 32 & $\begin{array}{l}22.3 \% \\
(0.173)\end{array}$ \\
\hline 2002 & 749 & $\begin{array}{c}3.1 \% \\
(0.087)\end{array}$ & 280 & $\begin{array}{c}8.2 \% \\
(0.126)\end{array}$ & 136 & $\begin{array}{l}16.3 \% \\
(0.141)\end{array}$ & 50 & $\begin{array}{c}23.4 \% \\
(0.191)\end{array}$ \\
\hline 2003 & 729 & $\begin{array}{c}4.0 \% \\
(0.098)\end{array}$ & 405 & $\begin{array}{c}7.2 \% \\
(0.122)\end{array}$ & 158 & $\begin{array}{l}17.5 \% \\
(0.144)\end{array}$ & 65 & $\begin{array}{c}24.0 \% \\
(0.17)\end{array}$ \\
\hline 2004 & 716 & $\begin{array}{c}3.8 \% \\
(0.095)\end{array}$ & 414 & $\begin{array}{c}6.5 \% \\
(0.118)\end{array}$ & 158 & $\begin{array}{l}16.1 \% \\
(0.146)\end{array}$ & 64 & $\begin{array}{l}21.9 \% \\
(0.201)\end{array}$ \\
\hline 2005 & 689 & $\begin{array}{c}3.9 \% \\
(0.098)\end{array}$ & 420 & $\begin{array}{c}6.4 \% \\
(0.119)\end{array}$ & 152 & $\begin{array}{l}16.6 \% \\
(0.151)\end{array}$ & 80 & $\begin{array}{l}20.6 \% \\
(0.188)\end{array}$ \\
\hline 2006 & 754 & $\begin{array}{c}4.1 \% \\
(0.099)\end{array}$ & 443 & $\begin{array}{c}6.9 \% \\
(0.121)\end{array}$ & 178 & $\begin{array}{l}16.2 \% \\
(0.149)\end{array}$ & 90 & $\begin{array}{c}20.9 \% \\
(0.185)\end{array}$ \\
\hline 2007 & 837 & $\begin{array}{c}3.4 \% \\
(0.088)\end{array}$ & 432 & $\begin{array}{c}6.6 \% \\
(0.114)\end{array}$ & 216 & $\begin{array}{c}12.4 \% \\
(0.138)\end{array}$ & 83 & $\begin{array}{l}19.5 \% \\
(0.186)\end{array}$ \\
\hline 2008 & 835 & $\begin{array}{c}4.2 \% \\
(0.109)\end{array}$ & 456 & $\begin{array}{c}7.7 \% \\
(0.138)\end{array}$ & 269 & $\begin{array}{l}12.6 \% \\
(0.163)\end{array}$ & 118 & $\begin{array}{c}20.1 \% \\
(0.213)\end{array}$ \\
\hline 2009 & 844 & $\begin{array}{c}3.2 \% \\
(0.088)\end{array}$ & 400 & $\begin{array}{c}6.6 \% \\
(0.118)\end{array}$ & 203 & $\begin{array}{l}12.3 \% \\
(0.145)\end{array}$ & 84 & $\begin{array}{l}18.7 \% \\
(0.199)\end{array}$ \\
\hline 2010 & 800 & $\begin{array}{c}3.5 \% \\
(0.091)\end{array}$ & 450 & $\begin{array}{c}6.1 \% \\
(0.114)\end{array}$ & 264 & $\begin{array}{l}10.2 \% \\
(0.135)\end{array}$ & 97 & $\begin{array}{l}17.4 \% \\
(0.193)\end{array}$ \\
\hline 2011 & 811 & $\begin{array}{c}3.8 \% \\
(0.099)\end{array}$ & 481 & $\begin{array}{c}6.3 \% \\
(0.122)\end{array}$ & 255 & $\begin{array}{l}11.6 \% \\
(0.148)\end{array}$ & 106 & $\begin{array}{l}18.4 \% \\
(0.205)\end{array}$ \\
\hline 2012 & 767 & $\begin{array}{c}4.0 \% \\
(0.097)\end{array}$ & 466 & $\begin{array}{c}6.6 \% \\
(0.118)\end{array}$ & 251 & $\begin{array}{l}12.0 \% \\
(0.139)\end{array}$ & 119 & $\begin{array}{c}18.1 \% \\
(0.178)\end{array}$ \\
\hline 2013 & 820 & $\begin{array}{c}3.3 \% \\
(0.079)\end{array}$ & 488 & $\begin{array}{l}5.6 \% \\
(0.097)\end{array}$ & 262 & $\begin{array}{l}10.1 \% \\
(0.114)\end{array}$ & 113 & $\begin{array}{c}15.7 \% \\
(0.147)\end{array}$ \\
\hline
\end{tabular}

Fonte: ANP e Finbra. Elaboração própria. Nas colunas, restringiu-se gradativamente a amostra de municípios que recebem royalties do petróleo, com a finalidade de verificar o percentual dessas rendas na receita orçamentária dos municípios mais beneficiados. Dados em valores reais calculados a partir do IPCA de 2016. Desvio padrão entre parêntesis.

Nesta dissertação, os resultados obtidos indicam que os royalties não têm impacto sobre a taxa de crescimento do PIB per capita local. Portanto, embora limitada ao setor de petróleo e derivados, observam-se indícios contrários à tese de MRN no país. Entretanto, assumindo que o orçamento público seja o principal canal pelo qual os efeitos dos royalties se manifestam, é preocupante a relação positiva entre tais receitas e despesas gerais dos municípios sem que sua população se beneficie efetivamente desses recursos de bens nãorenováveis.

Além desta introdução, este trabalho está dividido em mais seis capítulos: revisão da literatura pertinente; detalhamento da metodologia empregada; descrição dos dados 
utilizados; apresentação dos resultados obtidos; breve discussão de royalties, gasto público e desenvolvimento; e, por conseguinte, considerações finais da pesquisa.

\section{REVISÃO DA LITERATURA}

Na literatura econômica, a interação entre recursos naturais, crescimento e bemestar social está presente, em grande medida, nos trabalhos sobre a chamada Maldição dos Recursos Naturais (MRN), que relaciona abundância ou dependência ${ }^{10}$ em recursos naturais com taxas de crescimento relativamente menores. Mais especificamente, avalia-se a tese de que a exploração desses recursos impacta negativamente o crescimento econômico seja na forma direta ou indireta, por meio de outras variáveis. Entre as formas de explicar esse fenômeno, destacam-se a hipótese de "Doença Holandesa", a qual investiga os efeitos da produção e comercialização de recursos naturais sobre a competitividade dos demais setores da economia, e os trabalhos que focam em fatores políticos e institucionais, nos quais a qualidade institucional é vista como fundamental para formação da estrutura que faz a gestão das rendas desses bens não-renováveis.

Na primeira categoria, destacam-se os estudos de Sachs e Warner (1995, 1999, 2001), os quais encontraram evidências de que as taxas de crescimento do PIB de países em desenvolvimento tendem a ser negativamente correlacionadas com as exportações de recursos naturais. Mais especificamente, os autores concluíram que economias mais dependentes recursos naturais tendem a crescer mais lentamente do que as demais, entre outros fatores devido à mudança na composição do PIB, que se torna mais produtivo nos setores relacionados à indústria exportadora. Bravo-Ortega e Gregório (2005), por sua vez, também encontraram essa relação negativa, mas acrescentaram que mediante um estoque de capital humano significativo seria possível minimizar ou até mesmo reverter esse efeito adverso sobre o crescimento. No entanto, Alexeev e Conrad (2009) ${ }^{11}$, e Canuto e Cavallari (2012), em contraposição à essa evidência de MRN mostram que os royalties elevam o nível de PIB per capita, e consequentemente, afetam as taxas de crescimento de longo prazo dos países.

\footnotetext{
${ }^{10} \mathrm{Na}$ literatura, a dependência de recursos naturais é calculada através da razão entre exportação (ou produção) e PIB, ao passo que abundância é mensurada pela divisão entre rendimentos (ou nível de reservas) e população. Para informações mais detalhadas acerca das implicações do uso de cada uma das abordagens, bem como uma extensa revisão bibliográfica sobre MRN, ver Fernandes (2016).

${ }^{11}$ Alexeev e Conrad (2009) criticam o uso da taxa de crescimento do PIB como variável dependente nos modelos que visam obter o impacto dos royalties no PIB. O argumento é a possibilidade de um município crescer mais rapidamente durante os estágios iniciais de produção e reduzir o seu crescimento à medida em que as reservas forem se extinguindo; nesse caso, a desaceleração não necessariamente captaria ao impacto da dotação de royalties sobre o crescimento do PIB.
} 
Os trabalhos mencionados acima, bem como a maioria das pesquisas realizadas, investigam a MRN entre países. Enquanto países diferem em aspectos linguísticos, institucionais e culturais, os quais são difíceis de controlar em regressões de crescimento, essas disparidades tendem a ser menores em regiões de um mesmo país (Barro e Sala-iMartin, 1995). Com essa inspiração, Papyrakis e Gerlach (2007) e James e Aadland (2011) reproduziram a análise utilizando dados estaduais e municipais dos EUA, respectivamente. Ambos encontram indicativos de que a abundância de recursos naturais reduz a taxa de crescimento do PIB local. Papyrakis e Gerlach (2007) mostram que tais recursos afetam negativamente o crescimento por meio da redução de investimentos, do nível de escolaridade, da abertura comercial e dos gastos com pesquisa, e do aumento da corrupção. Adicionalmente, James e Aadland (2011) defendem as vantagens da análise intrapaís, como o aumento das observações amostrais (e, consequentemente, da confiança nas estimativas), a menor necessidade de controle de fatores políticos e institucionais e a possibilidade de examinar a MRN de forma localizada.

Voltando à análise entre países, na categoria seguinte, Mehlum, Moene e Torvik (2006) argumentam que a qualidade das instituições é o fator preponderante para o modo como recursos naturais afetam o crescimento econômico. No caso, sob instituições favoráveis, tais como percepção de respeito às leis e aos contratos, qualidade de governança e ausência de corrupção, determinados países poderiam usufruir plenamente da dotação de recursos. Ainda nessa linha, Robinson, Torvik e Verdier (2006) ponderam que a riqueza propiciada por tais bens estimula a má alocação de recursos na economia com a finalidade de assegurar a manutenção de cargos públicos (e.g.: políticas orçamentárias insustentáveis e elevação dos gastos com pessoal em setores do governo) ${ }^{12}$. Além disso, outros estudos a exemplo de Tornell e Lane (1999) e Lane e Tornell (1996) utilizam o conceito de rent seeking como forma de explicar as condições nas quais mais recursos naturais podem levar a um menor crescimento e redução do bem-estar. Segundo esses autores, dado que um aumento de sua exploração econômica gera um volume significativo de recursos para o Estado, criam-se incentivos para rent seeking (e.g.: corrupção; lobbies de empresas junto a governos em licitações, isenção de tarifas e subsídios) e isso desestimula o surgimento de iniciativas que

\footnotetext{
${ }^{12}$ No Brasil, as implicações de repasses de recursos para os municípios têm sido objeto de estudo de alguns trabalhos de economia política (Brollo e Nannicini, 2012; Monteiro e Ferraz, 2010), os quais apontam o papel preponderante de alianças partidárias no direcionamento de transferências intergovernamentais e o aumento da contratação de funcionários públicos em conjunto com maiores chances de reeleição pelo grupo da situação, respectivamente. Carnicelli e Postali (2014) também mostram evidências de incremento do funcionalismo público em resposta ao recebimento de royalties do petróleo.
} 
favoreçam o crescimento.

Toda essa discussão acerca do melhor aproveitamento de riquezas naturais nãorenováveis reflete a necessidade de assegurar os benefícios auferidos tanto para a geração atual, quanto posteriores. Nesse sentido, Hartwick (1977) foi precursor ao estabelecer a ideia de que os proventos da exploração desses bens fossem investidos em capital físico e humano, de modo a estabilizar o nível de consumo per capita ao longo do tempo - a Regra de Hartwick. Portanto, dada a natureza volátil (o volume de royalties é fortemente correlacionado com os preços internacionais do petróleo) e finita dessas receitas, impõem-se desafios na gestão desses recursos (Davis et al., 2001; Atkinson e Hamilton, 2003; Anshasy, 2011).

No Brasil, a evolução das rendas do petróleo transferidas aos municípios, conforme visto na introdução, incentivou um volume crescente de estudos relacionando o seu recebimento com a situação fiscal, social e econômica das localidades.

Com o intuito de analisar o efeito das rendas do petróleo sobre o padrão de vida dos brasileiros, Caselli e Michaels (2013) realizaram um amplo e relevante estudo no país. Primeiro, encontraram-se evidências de que o recebimento de tais receitas leva as municipalidades ampliarem os gastos com bens e serviços públicos (e.g.: infraestrutura, educação e saúde). Entretanto, tal qual Costa Nova (2005) e Monteiro e Ferraz (2010), os autores apontam que os indicadores socioeconômicos não refletem uma melhora condizente com o acréscimo de recursos proveniente de royalties. Por fim, os autores discutem tanto a qualidade do gasto, quanto a distribuição dessas rendas, visando à promoção de um uso mais eficiente. Ainda nessa análise entre royalties e indicadores sociais, Postali e Nishijima (2011, 2013), no primeiro artigo, tampouco encontraram indícios de que as transferências de rendas do petróleo tivessem impacto sobre o Índice FIRJAN de Desenvolvimento Municipal (IFDM); já no segundo estudo, eles obtiveram um efeito positivo sobre o acesso à energia elétrica, água encanada e coleta de lixo e negativo sobre a taxa de analfabetismo municipal.

No que concerne ao estudo fiscal, destacam-se os trabalhos de Postali (2015), Carnicelli e Postali (2012) e Postali e Rocha (2009). A partir do uso de distintas ferramentas metodológicas ${ }^{13}$, tais estudos procuraram avaliar os efeitos dos royalties sobre o esforço fiscal dos municípios. Seus resultados foram mistos, embora apenas o primeiro tenha apresentado evidências não significativas para um efeito perverso sobre as finanças locais.

\footnotetext{
${ }^{13}$ Fronteira estocástica de produção em Postali (2015), método do Duplo Robusto em Postali e Carnicelli (2012) e painel dinâmico de efeitos fixos em Postali e Rocha (2009).
} 
No entanto, são poucos os trabalhos que buscam investigar a MRN nesse contexto de royalties no país. O primeiro estudo da relação entre rendas petrolíferas e performance econômica a nível nacional foi de Postali (2009), que comparou a taxa de crescimento do PIB municipal antes e depois de $2000^{14}$ através de um estimador diff-in-diff. Os resultados apontaram que, no período analisado, os municípios receptores de royalties cresceram menos do que os demais - um indicativo de MRN no Brasil. Porém, é possível apontar algumas limitações nesse estudo, como a ausência de tratamento para a forte heterogeneidade nas características dos municípios que recebem as rendas do petróleo e para o fato de que a concessão de royalties, embora definida por lei, não seja aleatória (portanto, não configura um experimento genuíno). Já Monteiro e Ferraz (2010), embora com enfoque mais voltado para os efeitos políticos do recebimento dessas receitas, mostram que a produção de petróleo afeta a economia local somente através do orçamento do município, uma vez que $90 \%$ dessa produção ocorre no mar e não gera externalidades sobre a maioria das cidades com plataformas de petróleo em seu litoral. Adicionalmente, apesar de encontrarem um efeito positivo da produção de petróleo no nível de PIB per capita de municípios da região costeira, os autores apontam que o impacto é adverso sobre o PIB não industrial (isto é, PIB de serviços e agropecuário) per capita, sugerindo que essa atividade inibe o desenvolvimento de outras atividades econômicas numa espécie de "Doença Holandesa localizada".

Posta a contextualização e as principais contribuições acadêmicas, o capítulo seguinte apresenta o método utilizado nesta dissertação, o Duplamente Robusto.

\section{METODOLOGIA}

O procedimento de estimação utilizado é o Duplamente Robusto ${ }^{15}$ (Bang e Robins, 2005), que é composto de dois estágios. Inicialmente, usando um modelo logit, estima-se a probabilidade condicional de um município receber rendas de petróleo, isto é, o seu propensity score. Na etapa seguinte, as estimativas obtidas para cada munícipio são utilizadas como ponderadores das variáveis independentes do modelo de efeitos fixos, visando investigar o efeito dos royalties sobre o desenvolvimento econômico dos municípios tratados.

\footnotetext{
${ }^{14}$ Período a partir do qual, segundo o autor, os efeitos da Lei ${ }^{\circ}$ 9.478/97 (Lei do Petróleo) se tornaram mais evidentes.

${ }^{15}$ Estratégia de identificação também adotada em Galiani et al (2005) e Carnicelli e Postali (2012, 2014).
} 
O racional da estratégia de identificação utilizada é que, ao ponderar cada observação pelo propensity score, atribui-se um maior peso aos municípios do grupo de controle (não recebe royalties) que são mais parecidos com os do grupo de tratamento (recebe royalties) com base em atributos observados, tornando os dois grupos efetivamente comparáveis.

Baseado em Rosenbaum e Rubin (1983), segue uma breve descrição da metodologia do propensity score. Seja $Y(T)$ o resultado de um determinado tratamento T, sendo $\mathrm{T}=1$ quando a observação fizer parte do grupo de tratados e $\mathrm{T}=0$, caso contrário, ou seja, quando pertencente ao grupo de controle. Sob a validade das hipóteses de seleção probabilística $[0<P(T=1 \mid X)<1, \forall X]$ e unconfounded $[Y(T=1), Y(T=0)] \perp T \mid X]$, vale a ignorabilidade forte na seleção do tratamento:

$$
[Y(T=1), Y(T=0)] \perp T \mid P(T=1 \mid X)]
$$

Sendo $P(T=1 \mid X)$ a probabilidade receber o tratamento condicional a um vetor $\mathrm{X}$ de características observadas das unidades de interesse, no caso, os municípios. Essa propriedade indica que, dado $P(T=1 \mid X)$, os resultados potenciais independem do status de tratamento.

A hipótese de ignorabilidade forte permite reduzir um vetor de covariadas municipais a uma única variável e, portanto, aprimorar a comparabilidade entre os grupos de tratamento e de controle. Dessa forma, as unidades (pertencentes aos conjuntos de tratados e não-tratados) com propensity score semelhantes possuem, em probabilidade, o mesmo valor de X.

De acordo com Dehejia e Wahba (2002), a estimação do propensity score pode ser feita através de um modelo logit:

$$
P(T=1 \mid X)=F\left(\beta_{0}+\beta_{1} x_{1}+\cdots+\beta_{L} x_{L}\right)
$$

Sendo $\mathrm{F}($.$) uma função logística, x_{1}, \ldots, x_{L}$ um vetor de $\mathrm{L}$ covariadas com características socioeconômicas, geográficas e populacionais dos municípios e $\beta_{0}, \ldots, \beta_{L}$ os coeficientes a serem estimados.

Em seguida, antes da estimação do modelo de interesse, há a necessidade de testar o balanceamento das variáveis utilizadas na análise, ou seja, se o procedimento realizado efetivamente tornou os grupos de tratamento e de controle comparáveis entre si. Isso pode ser 
feito a partir de um teste t-Student para verificar se existe diferença significativa entre as médias das variáveis analisadas de ambos os grupos.

Constatado o balanceamento, Imbens e Wooldridge (2009) mostram que o uso dessas probabilidades estimadas como ponderador das variáveis independentes no estágio subsequente (painel de efeitos fixos, diff-in-diff ou outro método) reduz o viés de variável omitida da regressão. Em outras palavras, ao aperfeiçoar a comparação entre um município receptor de royalties com a sua contraparte do grupo de controle, eliminam-se potenciais vieses de variável omitida, configurando um ganho sobre a abordagem de efeitos fixos ou de painel dinâmico. Assim, visando obter o Efeito Médio do Tratamento sobre os Tratados (ATT ${ }^{16}$ ), Biondi et al. (2012) indicam a ponderação das observações das variáveis independentes do segundo estágio por:

$$
\begin{gathered}
\omega(T, X)=\left[T+(1-T) \frac{\operatorname{Prob}(T=1 \mid X)}{1-\operatorname{Prob}(T=1 \mid X)}\right] \frac{1}{\sum_{T_{n}=1}^{n} \operatorname{Prob}(T=1 \mid X)} \text {, ou seja, } \\
X a t t=\frac{X_{i}}{\sum_{T_{n}=1}^{n} \operatorname{Prob}(T=1 \mid X)} \text { se } T=1 \text { ou } \\
X a t t=\left[\frac{\operatorname{Prob}(T=1 \mid X)}{1-\operatorname{Prob}(T=1 \mid X)}\right] \frac{X_{i}}{\sum_{T_{n}=1}^{n} \operatorname{Prob}(T=1 \mid X)} \text { se } T=0
\end{gathered}
$$

Segundo Bang e Robins (2005), quando ao menos uma das etapas - o propensity score ou o modelo de regressão do segundo estágio - é especificada corretamente, obtêm-se estimadores consistentes (duplamente robustos). Eles acrescentam ainda que, dada a dificuldade em especificar corretamente tais procedimentos, essa dupla robustez é uma propriedade desejável.

Na etapa final, um modelo em painel de efeitos fixos é estimado com o objetivo de analisar o impacto dos royalties sobre a evolução do PIB dos munícipios beneficiados. A grande vantagem dessa abordagem é a possibilidade de controlar as características não observáveis das localidades, desde que permaneçam constantes no tempo. Logo, estima-se o seguinte modelo:

$$
\Delta \text { PIB per capita } i t=\alpha+f_{i}+\beta * \text { royalties per capita } i t+\gamma * X a t t_{i t}+\varepsilon_{i t}
$$

\footnotetext{
${ }^{16}$ Average Treatment Effect on Treated.
} 
Sendo que $\alpha$ é a constante da estimação, $f_{i}$ é o efeito fixo do município $i, \beta$ é o parâmetro de interesse que mensura a influência dos royalties sobre a taxa de crescimento do PIB per capita local, Xatt ${ }_{i t}$ representa o conjunto de variáveis de controle e $\varepsilon_{i t}$ é o termo de erro. Vale ressaltar que a hipótese de identificação utilizada é $E\left(\varepsilon_{i t} \mid\right.$ royalties per capita ${ }_{i t}, X_{\text {att }}$ it $)=0$, ou seja, assume-se a inexistência de correlação entre as variáveis especificadas no modelo e os demais fatores não controlados, de modo que os coeficientes sejam corretamente identificados (Wooldridge, 2002).

\section{BASE DE DADOS}

A base de dados da pesquisa é composta por um painel de 5570 municípios brasileiros observados entre 2004 e 2013, e formada a partir das seguintes fontes de informação: Agência Nacional do Petróleo (ANP), Finanças do Brasil (Finbra) e Instituto Brasileiro de Geografia e Estatística (IBGE), Federação das Indústrias do Estado do Rio de Janeiro (FIRJAN), Departamento de Informática do Sistema Único de Saúde (DATASUS) e Relação Anual de Informações Sociais (RAIS). Os dados sobre o volume de royalties de petróleo transferidos aos municípios são obtidos na ANP; informações relativas ao orçamento municipal são disponibilizadas no Finbra; os dados populacionais, geográficos e de atividade são divulgados pelo IBGE; os indicadores educacionais proveem da FIRJAN e da RAIS; já os de saúde são cedidos pela FIRJAN e pelo DATASUS.

Antes de prosseguir com a análise descritiva dos dados, é necessário fazer uma ressalva importante sobre os estudos empíricos em nível local, isto é, com base em estados e municípios. Geralmente, e neste caso não é diferente, tais pesquisas são limitadas pela indisponibilidade de informações, seja pelo fato das séries não serem muito longas, seja por simplesmente não existirem para tal nível de desagregação. Por exemplo, as séries históricas do IFDM (Índice FIRJAN de Desenvolvimento Municipal) e do número de trabalhadores formais com ensino superior completo começam em 2005 e 2006, respectivamente. Adicionalmente, sobre essa última variável, a ausência de dados desagregados (municipais) para o conjunto de trabalhadores formais e não-formais limitou o estudo apenas para o mercado formal.

Não bastasse essa dificuldade com relação à disponibilidade de dados, há o reconhecimento de que existem potenciais problemas metodológicos oriundos da composição das informações, especialmente no caso do PIB dos municípios. No Brasil, após o cômputo do 
PIB estadual, cada subsetor do PIB é atribuído aos municípios de acordo com critérios de referência. No caso específico do petróleo, o IBGE esclarece:

A metodologia empregada para repartir o VP [valor da produção] estadual da indústria extrativa mineral separa o petróleo do restante dos produtos da extrativa mineral. Em relação ao petróleo, a contribuição de cada município para a sua produção será estimada através da informação fornecida pela Agência Nacional do Petróleo sobre a composição dos royalties pagos pela Petrobrás a cada município. (IBGE, 2004, pp.18-19)

Em outras palavras, a participação de cada município na produção estadual de petróleo é estimada com base na informação reportada sobre os royalties recebidos pelos municípios ${ }^{17}$. Dado que a maior parte da produção petrolífera é realizada em plataformas marítimas, é evidente a dificuldade em associar tais dados de atividade com os respectivos municípios da costa nacional; dessa maneira, embora seja inadequado, é compreensível que o IBGE recorra a uma proxy em seus modelos para estimar quanto cada municipalidade produz do total estadual de petróleo e derivados.

A variável de interesse nesta dissertação é os royalties per capita repassados aos municípios. A Tabela 2 mostra as estatísticas descritivas dessa variável para os municípios receptores. A partir dela, é importante notar que o volume médio distribuído e o seu desvio padrão são crescentes ao longo do tempo, o que reflete uma grande disparidade na distribuição das rendas do petróleo.

Enquanto a maioria dos demais dados são autoexplicativos, é conveniente discorrer brevemente sobre o IFDM Geral. Ele possui variação entre 0 e 1 , sendo maior quanto melhor for o grau de desenvolvimento socioeconômico do município, e é formado pela média aritmética de três sub-índices: emprego e renda, educação e saúde. Estes, por sua vez, são calculados com base em médias diversos indicadores ${ }^{18}$, conforme a Tabela 3 . Neste trabalho, foram considerados os sub-índices de educação e de saúde como variáveis de controle para a qualificação da força de trabalho e para as condições de vida dos municípios. Contudo, como, por construção, tais indicadores são compostos por médias de outras variáveis, visando evitar a sobreposição dos dados e uma possível perda de variação no painel, optou-se por utilizar a quantidade de trabalhadores formais com ensino superior

\footnotetext{
${ }^{17}$ Para mais informações, consulte a Série Relatórios Metodológicos do IBGE, Produto Interno Bruto dos Municípios, volume 29, edição 2004.

${ }^{18}$ Para maiores informações acerca da metodologia do IFDM, ver o Anexo Metodológico disponibilizado pela FIRJAN.
} 
completo e o número de óbitos de crianças por causas evitáveis (um dos sub-componentes do IFDM Saúde) como os principais controles na regressão do $2^{\circ}$ estágio, fazendo uso dos subíndices do IFDM apenas em uma estimação alternativa.

Tabela 2 - Estatísticas Descritivas - Municípios Receptores de Royalties do Petróleo (em valores reais, per capita)

\begin{tabular}{lccccc}
\hline Ano & \# Observações & Média & Desvio Padrão & Mínimo & Máximo \\
& & & & & \\
\hline 1999 & 785 & 42.1 & 201.1 & 0.0022 & 3476.2 \\
2000 & 727 & 78.1 & 395.1 & 0.0021 & 6694.6 \\
2001 & 775 & 79.3 & 399.9 & 0.0023 & 6295.2 \\
2002 & 775 & 107.2 & 555.3 & 0.0023 & 9229.8 \\
2003 & 746 & 142.1 & 659.1 & 0.0033 & 10293.3 \\
2004 & 747 & 136.8 & 624.7 & 0.0030 & 9657.0 \\
2005 & 753 & 152.5 & 681.5 & 0.0030 & 10472.2 \\
2006 & 760 & 174.3 & 769.4 & 0.0032 & 11394.0 \\
2007 & 846 & 142.6 & 632.6 & 0.0029 & 12515.0 \\
2008 & 850 & 196.4 & 847.7 & 0.0026 & 12534.0 \\
2009 & 853 & 138.8 & 660.6 & $9.74 \mathrm{E}-06$ & 11494.6 \\
2010 & 814 & 167.6 & 753.5 & $1.01 \mathrm{E}-05$ & 14252.4 \\
2011 & 844 & 212.5 & 1168.8 & 0.0201 & 28166.1 \\
2012 & 841 & 241.5 & 1213.4 & $2.24 \mathrm{E}-06$ & 28412.1 \\
2013 & 882 & 222.0 & 1152.7 & $3.38 \mathrm{E}-08$ & 28758.8 \\
\hline
\end{tabular}

Fonte: ANP. Elaboração própria. Dados em valores reais calculados a partir do IPCA de 2016.

Tabela 3 - Composição do IFDM

\begin{tabular}{|c|c|c|}
\hline Sub-Índice & Componentes & Fonte \\
\hline Emprego e Renda & $\begin{array}{l}\text { Geração de emprego formal } \\
\text { Absorção de mão de obra local } \\
\text { Geração de renda formal } \\
\text { Salários médios de emprego formal } \\
\text { Desigualdade }\end{array}$ & Ministério do Trabalho e Emprego \\
\hline Educação & $\begin{array}{l}\text { Matrículas na educação infantil } \\
\text { Abandono no ensino fundamental } \\
\text { Distorção idade-série no ensino fundamental } \\
\text { Docentes com ensino superior no ensino fundamental } \\
\text { Média de horas aula diárias no ensino fundamental } \\
\text { Resultado do IDEB no ensino fundamental }\end{array}$ & Ministério da Educação \\
\hline Saúde & $\begin{array}{l}\text { Número de consultas pré-natal } \\
\text { Óbitos por causas mal-definidas } \\
\text { Óbitos de crianças por causas evitáveis } \\
\text { Internação sensível à atenção básica }\end{array}$ & Ministério da Saúde \\
\hline
\end{tabular}


As Tabelas 4 e 5, por sua vez, sintetizam as estatísticas descritivas (média e desvio padrão) de todos os dados analisados para as municipalidades tratadas e não-tratadas, respectivamente. Primeiramente, vale salientar que, em média, 15\% do total de municípios receberam royalties do petróleo no período analisado. A partir da comparação entre os grupos, observa-se que os tratados possuem, em média, mais população e um PIB menos intensivo em atividades agropecuárias, o que é condizente com o fato da produção nacional de petróleo ser concentrada majoritariamente em regiões litorâneas. Além disso, a respeito da evolução do PIB per capita, tanto em nível ou em taxa de crescimento, não há preponderância de um grupo sobre o outro; entretanto, em 2010, nota-se um forte crescimento médio dos municípios tratados, que possivelmente pode ser explicado por efeito base via recuperação da economia mundial após a Crise Financeira Internacional e sua influência nos preços internacionais de petróleo.

Em termos de orçamento público, os munícipios não-tratados possuem acesso a um volume médio maior de receitas orçamentárias e correntes, puxado pelas receitas de transferências intergovernamentais; por outro lado, os tratados apresentam, em média, mais receitas tributárias, o que inicialmente sugere evidência contrária (cuja verificação foge ao escopo deste trabalho) à tese de que as rendas de recursos naturais reduzem o incentivo das localidades em buscar recursos próprios (Collier, 2007; Postali e Rocha, 2009). No que concerne às despesas, observa-se que os tratados têm dispêndio médio maior com educação e cultura, ao passo que nas demais categorias analisadas - investimentos, pessoal, saúde e saneamento - os não-tratados apresentam gastos médios maiores.

Por fim, os IFDM Saúde e Educação de ambos os grupos têm trajetórias crescentes no período considerado - um indicativo de melhora nas condições de vida e de qualificação da população; no entanto, os não-tratados possuem nível maior em ambos indicadores, mesmo tendo gasto público médio menor com educação (conforme parágrafo anterior). Já os tratados têm em média um nível menor em óbitos de crianças por causas evitáveis, novamente em consonância com a evolução apontada pelo IFDM Saúde. 
Tabela 4 - Estatísticas Descritivas - Municípios Brasileiros Tratados

\begin{tabular}{|c|c|c|c|c|c|c|c|c|c|c|}
\hline Média & 2004 & 2005 & 2006 & 2007 & 2008 & 2009 & 2010 & 2011 & 2012 & 2013 \\
\hline PIB per capita & $\begin{array}{c}12283 \\
(19184)\end{array}$ & $\begin{array}{c}13472 \\
(22758)\end{array}$ & $\begin{array}{c}14640 \\
(24894)\end{array}$ & $\begin{array}{c}15388 \\
(25735)\end{array}$ & $\begin{array}{c}16421 \\
(28127)\end{array}$ & $\begin{array}{c}16132 \\
(26609)\end{array}$ & $\begin{array}{c}19065 \\
(33908)\end{array}$ & $\begin{array}{c}20922 \\
(42838)\end{array}$ & $\begin{array}{c}21904 \\
(47085)\end{array}$ & $\begin{array}{c}21983 \\
(42071)\end{array}$ \\
\hline PIB Agrícola / PIB & $\begin{array}{c}0.16 \\
(0.13)\end{array}$ & $\begin{array}{c}0.14 \\
(0.12)\end{array}$ & $\begin{array}{c}0.15 \\
(0.12)\end{array}$ & $\begin{array}{c}0.15 \\
(0.13)\end{array}$ & $\begin{array}{c}0.14 \\
(0.12)\end{array}$ & $\begin{array}{c}0.14 \\
(0.11)\end{array}$ & $\begin{array}{c}0.14 \\
(0.12)\end{array}$ & $\begin{array}{c}0.13 \\
(0.11)\end{array}$ & $\begin{array}{c}0.11 \\
(0.12)\end{array}$ & $\begin{array}{c}0.12 \\
(0.11)\end{array}$ \\
\hline Taxa de Crescimento do PIB per capita (anual) & $\begin{array}{c}0.02 \\
(0.11)\end{array}$ & $\begin{array}{c}0.06 \\
(0.12)\end{array}$ & $\begin{array}{l}0.08 \\
(0.1)\end{array}$ & $\begin{array}{c}0.07 \\
(0.17)\end{array}$ & $\begin{array}{c}0.04 \\
(0.14)\end{array}$ & $\begin{array}{c}0.03 \\
(0.14)\end{array}$ & $\begin{array}{c}0.16 \\
(0.24)\end{array}$ & $\begin{array}{c}0.06 \\
(0.15)\end{array}$ & $\begin{array}{c}0.03 \\
(0.19)\end{array}$ & $\begin{array}{c}0.02 \\
(0.15)\end{array}$ \\
\hline Taxa de Crescimento do PIB Ex-Industrial per capita (anual) & $\begin{array}{l}0.00 \\
(0.1)\end{array}$ & $\begin{array}{c}0.05 \\
(0.11)\end{array}$ & $\begin{array}{l}0.09 \\
(0.1)\end{array}$ & $\begin{array}{c}0.08 \\
(0.15)\end{array}$ & $\begin{array}{c}0.03 \\
(0.11)\end{array}$ & $\begin{array}{c}0.06 \\
(0.13)\end{array}$ & $\begin{array}{c}0.17 \\
(0.24)\end{array}$ & $\begin{array}{c}0.06 \\
(0.11)\end{array}$ & $\begin{array}{c}0.03 \\
(0.12)\end{array}$ & $\begin{array}{c}0.03 \\
(0.11)\end{array}$ \\
\hline Royalties per capita & $\begin{array}{c}137 \\
(625)\end{array}$ & $\begin{array}{c}152 \\
(681)\end{array}$ & $\begin{array}{c}174 \\
(769)\end{array}$ & $\begin{array}{c}143 \\
(633)\end{array}$ & $\begin{array}{c}196 \\
(848)\end{array}$ & $\begin{array}{c}139 \\
(661)\end{array}$ & $\begin{array}{c}168 \\
(754)\end{array}$ & $\begin{array}{c}212 \\
(1169)\end{array}$ & $\begin{array}{c}241 \\
(1213)\end{array}$ & $\begin{array}{c}222 \\
(1153)\end{array}$ \\
\hline População Municipal & $\begin{array}{c}80184 \\
(485022)\end{array}$ & $\begin{array}{c}82711 \\
(487976)\end{array}$ & $\begin{array}{c}83517 \\
(490166)\end{array}$ & $\begin{array}{c}77267 \\
(461656)\end{array}$ & $\begin{array}{c}79085 \\
(465904)\end{array}$ & $\begin{array}{c}80447 \\
(468074)\end{array}$ & $\begin{array}{c}78204 \\
(479303)\end{array}$ & $\begin{array}{c}78107 \\
(474319)\end{array}$ & $\begin{array}{c}78731 \\
(477868)\end{array}$ & $\begin{array}{c}82282 \\
(485600)\end{array}$ \\
\hline IFDM Emprego e Renda & $\begin{array}{l}-- \\
--\end{array}$ & $\begin{array}{c}0.47 \\
(0.14)\end{array}$ & $\begin{array}{c}0.49 \\
(0.14)\end{array}$ & $\begin{array}{c}0.47 \\
(0.14)\end{array}$ & $\begin{array}{c}0.46 \\
(0.14)\end{array}$ & $\begin{array}{c}0.49 \\
(0.13)\end{array}$ & $\begin{array}{c}0.49 \\
(0.14)\end{array}$ & $\begin{array}{c}0.48 \\
(0.14)\end{array}$ & $\begin{array}{c}0.49 \\
(0.13)\end{array}$ & $\begin{array}{c}0.48 \\
(0.13)\end{array}$ \\
\hline Óbitos Evitáveis de Crianças (por 100 mil habitantes) & $\begin{array}{c}42 \\
(22)\end{array}$ & $\begin{array}{c}41 \\
(24)\end{array}$ & $\begin{array}{c}37 \\
(21)\end{array}$ & $\begin{array}{c}35 \\
(17)\end{array}$ & $\begin{array}{c}31 \\
(16)\end{array}$ & $\begin{array}{c}31 \\
(16)\end{array}$ & $\begin{array}{c}29 \\
(14)\end{array}$ & $\begin{array}{c}27 \\
\text { (14) }\end{array}$ & $\begin{array}{c}27 \\
\text { (14) }\end{array}$ & $\begin{array}{c}25 \\
(13)\end{array}$ \\
\hline IFDM Saúde & -- & $\begin{array}{l}0.53 \\
(0.2)\end{array}$ & $\begin{array}{c}0.56 \\
(0.19)\end{array}$ & $\begin{array}{c}0.58 \\
(0.19)\end{array}$ & $\begin{array}{c}0.61 \\
(0.18)\end{array}$ & $\begin{array}{c}0.63 \\
(0.18)\end{array}$ & $\begin{array}{c}0.63 \\
(0.17)\end{array}$ & $\begin{array}{c}0.65 \\
(0.17)\end{array}$ & $\begin{array}{c}0.66 \\
(0.16)\end{array}$ & $\begin{array}{c}0.68 \\
(0.16)\end{array}$ \\
\hline Trab. Formais com Superior Completo (por 100 mil habitantes) & $\begin{array}{l}-- \\
--\end{array}$ & $\begin{array}{l}-- \\
--\end{array}$ & $\begin{array}{c}1234 \\
(1895)\end{array}$ & $\begin{array}{c}1418 \\
(1820)\end{array}$ & $\begin{array}{c}1520 \\
(1900)\end{array}$ & $\begin{array}{c}1720 \\
(1946)\end{array}$ & $\begin{array}{c}1829 \\
(2139)\end{array}$ & $\begin{array}{c}2010 \\
(2236)\end{array}$ & $\begin{array}{c}2167 \\
(2432)\end{array}$ & $\begin{array}{c}2646 \\
(5935)\end{array}$ \\
\hline IFDM Educação & $\begin{array}{l}-- \\
--\end{array}$ & $\begin{array}{c}0.52 \\
(0.17)\end{array}$ & $\begin{array}{c}0.52 \\
(0.17)\end{array}$ & $\begin{array}{c}0.56 \\
(0.15)\end{array}$ & $\begin{array}{c}0.58 \\
(0.15)\end{array}$ & $\begin{array}{c}0.60 \\
(0.14)\end{array}$ & $\begin{array}{c}0.63 \\
(0.14)\end{array}$ & $\begin{array}{c}0.66 \\
(0.14)\end{array}$ & $\begin{array}{c}0.67 \\
(0.13)\end{array}$ & $\begin{array}{c}0.70 \\
(0.12)\end{array}$ \\
\hline Receita Orçamentária per capita & $\begin{array}{c}1674 \\
(1294)\end{array}$ & $\begin{array}{c}1826 \\
(1278)\end{array}$ & $\begin{array}{c}2032 \\
(1401)\end{array}$ & $\begin{array}{c}2148 \\
(1359)\end{array}$ & $\begin{array}{c}2427 \\
(1541)\end{array}$ & $\begin{array}{c}2346 \\
(1488)\end{array}$ & $\begin{array}{c}2631 \\
(1667)\end{array}$ & $\begin{array}{c}2883 \\
(1881)\end{array}$ & $\begin{array}{c}3061 \\
(2220)\end{array}$ & $\begin{array}{c}3126 \\
(1784)\end{array}$ \\
\hline Receita Corrente per capita & $\begin{array}{c}1746 \\
(1359)\end{array}$ & $\begin{array}{c}1923 \\
(1326)\end{array}$ & $\begin{array}{c}2098 \\
(1440)\end{array}$ & $\begin{array}{c}2250 \\
(1416)\end{array}$ & $\begin{array}{c}2524 \\
(1605)\end{array}$ & $\begin{array}{c}2464 \\
(1529)\end{array}$ & $\begin{array}{c}2721 \\
(1733)\end{array}$ & $\begin{array}{c}3040 \\
(1983)\end{array}$ & $\begin{array}{c}3175 \\
(2301)\end{array}$ & $\begin{array}{c}3015 \\
(1737)\end{array}$ \\
\hline Receita Tributária per capita & $\begin{array}{c}144 \\
(285)\end{array}$ & $\begin{array}{c}164 \\
(296)\end{array}$ & $\begin{array}{c}170 \\
(291)\end{array}$ & $\begin{array}{c}184 \\
(320)\end{array}$ & $\begin{array}{c}196 \\
(335)\end{array}$ & $\begin{array}{c}213 \\
(366)\end{array}$ & $\begin{array}{c}225 \\
(395)\end{array}$ & $\begin{array}{c}249 \\
(421)\end{array}$ & $\begin{array}{c}270 \\
(451)\end{array}$ & $\begin{array}{c}267 \\
(437)\end{array}$ \\
\hline Receita de Transferências per capita & $\begin{array}{c}1468 \\
(1077)\end{array}$ & $\begin{array}{c}1639 \\
(1098)\end{array}$ & $\begin{array}{c}1813 \\
(1235)\end{array}$ & $\begin{array}{c}1937 \\
(1174)\end{array}$ & $\begin{array}{c}2196 \\
(1386)\end{array}$ & $\begin{array}{c}2122 \\
(1265)\end{array}$ & $\begin{array}{c}2356 \\
(1452)\end{array}$ & $\begin{array}{c}2627 \\
(1676)\end{array}$ & $\begin{array}{c}2675 \\
(1473)\end{array}$ & $\begin{array}{c}2602 \\
(1434)\end{array}$ \\
\hline Receita Orçamentária / Despesa Orçamentária & $\begin{array}{c}1.03 \\
(0.08)\end{array}$ & $\begin{array}{c}1.03 \\
(0.09)\end{array}$ & $\begin{array}{c}1.01 \\
(0.08)\end{array}$ & $\begin{array}{c}1.02 \\
(0.09)\end{array}$ & $\begin{array}{c}1.04 \\
(0.11)\end{array}$ & $\begin{array}{c}1.07 \\
(0.16)\end{array}$ & $\begin{array}{c}1.17 \\
(2.02)\end{array}$ & $\begin{array}{c}1.09 \\
(0.11)\end{array}$ & $\begin{array}{c}1.07 \\
(0.09)\end{array}$ & $\begin{array}{l}1.19 \\
(0.1)\end{array}$ \\
\hline Despesa com Investimentos per capita & $\begin{array}{c}197 \\
(429)\end{array}$ & $\begin{array}{c}166 \\
(288)\end{array}$ & $\begin{array}{c}230 \\
(397)\end{array}$ & $\begin{array}{c}203 \\
(245)\end{array}$ & $\begin{array}{c}270 \\
(308)\end{array}$ & $\begin{array}{c}154 \\
(244)\end{array}$ & $\begin{array}{c}222 \\
(335)\end{array}$ & $\begin{array}{c}211 \\
(242)\end{array}$ & $\begin{array}{c}268 \\
(340)\end{array}$ & $\begin{array}{c}145 \\
(147)\end{array}$ \\
\hline Despesa com Pessoal per capita & $\begin{array}{c}708 \\
(498)\end{array}$ & $\begin{array}{c}781 \\
(460)\end{array}$ & $\begin{array}{c}882 \\
(513)\end{array}$ & $\begin{array}{c}970 \\
(542)\end{array}$ & $\begin{array}{l}1039 \\
(571)\end{array}$ & $\begin{array}{l}1104 \\
(600)\end{array}$ & $\begin{array}{l}1181 \\
(618)\end{array}$ & $\begin{array}{l}1312 \\
(644)\end{array}$ & $\begin{array}{l}1414 \\
(748)\end{array}$ & $\begin{array}{l}1464 \\
(734)\end{array}$ \\
\hline Despesa com Saúde e Saneamento per capita & $\begin{array}{c}346 \\
(286)\end{array}$ & $\begin{array}{c}388 \\
(283)\end{array}$ & $\begin{array}{c}450 \\
(353)\end{array}$ & $\begin{array}{c}463 \\
(307)\end{array}$ & $\begin{array}{c}516 \\
(324)\end{array}$ & $\begin{array}{c}545 \\
(360)\end{array}$ & $\begin{array}{c}589 \\
(408)\end{array}$ & $\begin{array}{c}628 \\
(368)\end{array}$ & $\begin{array}{c}674 \\
(424)\end{array}$ & $\begin{array}{c}624 \\
(383)\end{array}$ \\
\hline Despesa com Educação e Cultura per capita & $\begin{array}{c}474 \\
(264)\end{array}$ & $\begin{array}{c}529 \\
(259)\end{array}$ & $\begin{array}{c}607 \\
(290)\end{array}$ & $\begin{array}{c}655 \\
\text { (291) }\end{array}$ & $\begin{array}{c}726 \\
(305)\end{array}$ & $\begin{array}{c}746 \\
\text { (322) }\end{array}$ & $\begin{array}{c}855 \\
(352)\end{array}$ & $\begin{array}{c}942 \\
(402)\end{array}$ & $\begin{array}{c}979 \\
(400)\end{array}$ & $\begin{array}{c}893 \\
(341)\end{array}$ \\
\hline \# Municípios & 747 & 753 & 760 & 846 & 850 & 853 & 814 & 844 & 841 & 882 \\
\hline
\end{tabular}


Tabela 5 - Estatísticas Descritivas - Municípios Brasileiros Não Tratados

\begin{tabular}{|c|c|c|c|c|c|c|c|c|c|c|}
\hline Média & 2004 & 2005 & 2006 & 2007 & 2008 & 2009 & 2010 & 2011 & 2012 & 2013 \\
\hline $\mathrm{PIB}$ per capita & $\begin{array}{c}14586 \\
(16587)\end{array}$ & $\begin{array}{c}14133 \\
(15267)\end{array}$ & $\begin{array}{c}15005 \\
(15965)\end{array}$ & $\begin{array}{c}16255 \\
(16791)\end{array}$ & $\begin{array}{c}17256 \\
(17198)\end{array}$ & $\begin{array}{c}17668 \\
(16976)\end{array}$ & $\begin{array}{c}18767 \\
(19147)\end{array}$ & $\begin{array}{c}20142 \\
(20208)\end{array}$ & $\begin{array}{c}20732 \\
(20271)\end{array}$ & $\begin{array}{c}21704 \\
(20540)\end{array}$ \\
\hline PIB Agrícola / PIB & $\begin{array}{c}0.27 \\
(0.17)\end{array}$ & $\begin{array}{c}0.25 \\
(0.16)\end{array}$ & $\begin{array}{c}0.24 \\
(0.15)\end{array}$ & $\begin{array}{c}0.24 \\
(0.15)\end{array}$ & $\begin{array}{c}0.25 \\
(0.16)\end{array}$ & $\begin{array}{c}0.24 \\
(0.16)\end{array}$ & $\begin{array}{c}0.21 \\
(0.15)\end{array}$ & $\begin{array}{c}0.22 \\
(0.15)\end{array}$ & $\begin{array}{c}0.20 \\
(0.15)\end{array}$ & $\begin{array}{c}0.21 \\
(0.16)\end{array}$ \\
\hline Taxa de Crescimento do PIB per capita (anual) & $\begin{array}{c}0.01 \\
(0.13)\end{array}$ & $\begin{array}{c}0.00 \\
(0.14)\end{array}$ & $\begin{array}{c}0.07 \\
(0.14)\end{array}$ & $\begin{array}{c}0.08 \\
(0.16)\end{array}$ & $\begin{array}{c}0.06 \\
(0.14)\end{array}$ & $\begin{array}{c}0.03 \\
(0.12)\end{array}$ & $\begin{array}{c}0.05 \\
(0.25)\end{array}$ & $\begin{array}{c}0.07 \\
(0.13)\end{array}$ & $\begin{array}{c}0.03 \\
(0.15)\end{array}$ & $\begin{array}{c}0.05 \\
(0.17)\end{array}$ \\
\hline Taxa de Crescimento do PIB Ex-Industrial per capita (anual) & $\begin{array}{c}0.00 \\
(0.13)\end{array}$ & $\begin{array}{c}0.00 \\
(0.14)\end{array}$ & $\begin{array}{c}0.07 \\
(0.14)\end{array}$ & $\begin{array}{c}0.08 \\
(0.16)\end{array}$ & $\begin{array}{c}0.07 \\
(0.13)\end{array}$ & $\begin{array}{c}0.03 \\
(0.12)\end{array}$ & $\begin{array}{c}0.06 \\
(0.21)\end{array}$ & $\begin{array}{c}0.07 \\
(0.11)\end{array}$ & $\begin{array}{c}0.03 \\
(0.14)\end{array}$ & $\begin{array}{c}0.06 \\
(0.15)\end{array}$ \\
\hline População Municipal & $\begin{array}{c}25280 \\
(84056)\end{array}$ & $\begin{array}{c}25338 \\
(85028)\end{array}$ & $\begin{array}{c}25666 \\
(86537)\end{array}$ & $\begin{array}{c}25121 \\
(86660)\end{array}$ & $\begin{array}{c}25961 \\
(88859)\end{array}$ & $\begin{array}{c}26079 \\
(89564)\end{array}$ & $\begin{array}{c}26750 \\
(92530)\end{array}$ & $\begin{array}{c}26786 \\
(93286)\end{array}$ & $\begin{array}{c}27039 \\
(94174)\end{array}$ & $\begin{array}{c}27402 \\
(94513)\end{array}$ \\
\hline IFDM Emprego e Renda & $\begin{array}{l}-- \\
--\end{array}$ & $\begin{array}{c}0.45 \\
(0.15)\end{array}$ & $\begin{array}{c}0.48 \\
(0.14)\end{array}$ & $\begin{array}{c}0.47 \\
(0.14)\end{array}$ & $\begin{array}{c}0.45 \\
(0.15)\end{array}$ & $\begin{array}{c}0.48 \\
(0.14)\end{array}$ & $\begin{array}{c}0.48 \\
(0.15)\end{array}$ & $\begin{array}{c}0.48 \\
(0.15)\end{array}$ & $\begin{array}{c}0.49 \\
(0.15)\end{array}$ & $\begin{array}{c}0.48 \\
(0.14)\end{array}$ \\
\hline Óbitos Evitáveis de Crianças (por 100 mil habitantes) & $\begin{array}{c}43 \\
(33)\end{array}$ & $\begin{array}{c}41 \\
(30)\end{array}$ & $\begin{array}{c}38 \\
(28)\end{array}$ & $\begin{array}{c}36 \\
(25)\end{array}$ & $\begin{array}{c}34 \\
(22)\end{array}$ & $\begin{array}{c}32 \\
(23)\end{array}$ & $\begin{array}{c}30 \\
(21)\end{array}$ & $\begin{array}{c}30 \\
(20)\end{array}$ & $\begin{array}{c}29 \\
(20)\end{array}$ & $\begin{array}{c}28 \\
(20)\end{array}$ \\
\hline IFDM Saúde & $\begin{array}{l}-- \\
--\end{array}$ & $\begin{array}{l}0.59 \\
(0.2)\end{array}$ & $\begin{array}{c}0.61 \\
(0.19)\end{array}$ & $\begin{array}{c}0.64 \\
(0.18)\end{array}$ & $\begin{array}{c}0.66 \\
(0.17)\end{array}$ & $\begin{array}{c}0.67 \\
(0.17)\end{array}$ & $\begin{array}{c}0.68 \\
(0.16)\end{array}$ & $\begin{array}{c}0.70 \\
(0.16)\end{array}$ & $\begin{array}{c}0.72 \\
(0.15)\end{array}$ & $\begin{array}{c}0.73 \\
(0.15)\end{array}$ \\
\hline Trab. Formais com Superior Completo (por 100 mil habitantes) & $\begin{array}{l}-- \\
--\end{array}$ & $\begin{array}{l}-- \\
--\end{array}$ & $\begin{array}{c}1218 \\
(1162)\end{array}$ & $\begin{array}{c}1498 \\
(1270)\end{array}$ & $\begin{array}{c}1610 \\
(1353)\end{array}$ & $\begin{array}{c}1768 \\
(1423)\end{array}$ & $\begin{array}{c}1922 \\
(1525)\end{array}$ & $\begin{array}{c}2089 \\
(1646)\end{array}$ & $\begin{array}{c}2234 \\
(1755)\end{array}$ & $\begin{array}{c}2455 \\
(1734)\end{array}$ \\
\hline IFDM Educação & $\begin{array}{l}-- \\
--\end{array}$ & $\begin{array}{c}0.56 \\
(0.19)\end{array}$ & $\begin{array}{c}0.56 \\
(0.19)\end{array}$ & $\begin{array}{c}0.63 \\
(0.14)\end{array}$ & $\begin{array}{c}0.64 \\
(0.14)\end{array}$ & $\begin{array}{c}0.67 \\
(0.13)\end{array}$ & $\begin{array}{c}0.69 \\
(0.13)\end{array}$ & $\begin{array}{c}0.71 \\
(0.12)\end{array}$ & $\begin{array}{c}0.72 \\
(0.12)\end{array}$ & $\begin{array}{c}0.75 \\
(0.12)\end{array}$ \\
\hline Receita Orçamentária per capita & $\begin{array}{l}1755 \\
(950)\end{array}$ & $\begin{array}{c}1949 \\
(1049)\end{array}$ & $\begin{array}{c}2149 \\
(1130)\end{array}$ & $\begin{array}{c}2383 \\
(1971)\end{array}$ & $\begin{array}{c}2631 \\
(1291)\end{array}$ & $\begin{array}{c}2523 \\
(1184)\end{array}$ & $\begin{array}{c}2788 \\
(1316)\end{array}$ & $\begin{array}{c}3060 \\
(3720)\end{array}$ & $\begin{array}{c}3195 \\
(1477)\end{array}$ & $\begin{array}{c}3450 \\
(1661)\end{array}$ \\
\hline Receita Corrente per capita & $\begin{array}{c}1842 \\
(1002)\end{array}$ & $\begin{array}{c}2074 \\
(1114)\end{array}$ & $\begin{array}{c}2224 \\
(1177)\end{array}$ & $\begin{array}{c}2497 \\
(2014)\end{array}$ & $\begin{array}{c}2740 \\
(1357)\end{array}$ & $\begin{array}{c}2687 \\
(1283)\end{array}$ & $\begin{array}{c}2898 \\
(1402)\end{array}$ & $\begin{array}{c}3254 \\
(3970)\end{array}$ & $\begin{array}{c}3302 \\
(1583)\end{array}$ & $\begin{array}{c}3257 \\
(1547)\end{array}$ \\
\hline Receita Tributária per capita & $\begin{array}{c}102 \\
(124)\end{array}$ & $\begin{array}{c}112 \\
(135)\end{array}$ & $\begin{array}{c}124 \\
(149)\end{array}$ & $\begin{array}{c}146 \\
(316)\end{array}$ & $\begin{array}{c}153 \\
(184)\end{array}$ & $\begin{array}{c}155 \\
(183)\end{array}$ & $\begin{array}{c}180 \\
(228)\end{array}$ & $\begin{array}{c}201 \\
(427)\end{array}$ & $\begin{array}{c}213 \\
(249)\end{array}$ & $\begin{array}{c}212 \\
(287)\end{array}$ \\
\hline Receita de Transferências per capita & $\begin{array}{l}1626 \\
(899)\end{array}$ & $\begin{array}{c}1845 \\
(1016)\end{array}$ & $\begin{array}{c}1976 \\
(1074)\end{array}$ & $\begin{array}{c}2200 \\
(1543)\end{array}$ & $\begin{array}{c}2441 \\
(1243)\end{array}$ & $\begin{array}{c}2386 \\
(1178)\end{array}$ & $\begin{array}{c}2554 \\
(1272)\end{array}$ & $\begin{array}{c}2866 \\
(3562)\end{array}$ & $\begin{array}{c}2879 \\
(1423)\end{array}$ & $\begin{array}{c}2882 \\
(1420)\end{array}$ \\
\hline Receita Orçamentária / Despesa Orçamentária & $\begin{array}{c}1.03 \\
(0.08)\end{array}$ & $\begin{array}{c}1.04 \\
(0.08)\end{array}$ & $\begin{array}{c}1.02 \\
(0.16)\end{array}$ & $\begin{array}{c}1.06 \\
(1.54)\end{array}$ & $\begin{array}{c}1.06 \\
(1.47)\end{array}$ & $\begin{array}{c}1.09 \\
(0.66)\end{array}$ & $\begin{array}{c}14.86 \\
(892.05)\end{array}$ & $\begin{array}{c}1.09 \\
(0.12)\end{array}$ & $\begin{array}{c}1.08 \\
(0.14)\end{array}$ & $\begin{array}{c}1.22 \\
(0.12)\end{array}$ \\
\hline Despesa com Investimentos per capita & $\begin{array}{c}188 \\
(225)\end{array}$ & $\begin{array}{c}176 \\
(211)\end{array}$ & $\begin{array}{c}261 \\
(260)\end{array}$ & $\begin{array}{c}258 \\
(293)\end{array}$ & $\begin{array}{c}368 \\
(366)\end{array}$ & $\begin{array}{c}199 \\
(227)\end{array}$ & $\begin{array}{c}277 \\
(272)\end{array}$ & $\begin{array}{c}272 \\
(278)\end{array}$ & $\begin{array}{c}354 \\
(343)\end{array}$ & $\begin{array}{c}206 \\
(211)\end{array}$ \\
\hline Despesa com Pessoal per capita & $\begin{array}{c}736 \\
(375)\end{array}$ & $\begin{array}{c}813 \\
\text { (394) }\end{array}$ & $\begin{array}{c}900 \\
(440)\end{array}$ & $\begin{array}{l}1013 \\
(884)\end{array}$ & $\begin{array}{l}1068 \\
(479)\end{array}$ & $\begin{array}{l}1137 \\
(580)\end{array}$ & $\begin{array}{l}1204 \\
(576)\end{array}$ & $\begin{array}{c}1323 \\
(1947)\end{array}$ & $\begin{array}{l}1415 \\
(616)\end{array}$ & $\begin{array}{l}1483 \\
(625)\end{array}$ \\
\hline Despesa com Saúde e Saneamento per capita & $\begin{array}{c}367 \\
(212)\end{array}$ & $\begin{array}{c}421 \\
(221)\end{array}$ & $\begin{array}{c}491 \\
(245)\end{array}$ & $\begin{array}{c}531 \\
(449)\end{array}$ & $\begin{array}{c}579 \\
(273)\end{array}$ & $\begin{array}{c}583 \\
(264)\end{array}$ & $\begin{array}{c}635 \\
(288)\end{array}$ & $\begin{array}{c}684 \\
(847)\end{array}$ & $\begin{array}{c}754 \\
(355)\end{array}$ & $\begin{array}{c}695 \\
(329)\end{array}$ \\
\hline Despesa com Educação e Cultura per capita & $\begin{array}{c}476 \\
(240)\end{array}$ & $\begin{array}{c}529 \\
(248)\end{array}$ & $\begin{array}{c}588 \\
(271)\end{array}$ & $\begin{array}{c}655 \\
(567)\end{array}$ & $\begin{array}{c}698 \\
(281)\end{array}$ & $\begin{array}{c}708 \\
(266)\end{array}$ & $\begin{array}{c}775 \\
\text { (298) }\end{array}$ & $\begin{array}{c}868 \\
(1317)\end{array}$ & $\begin{array}{c}924 \\
(355)\end{array}$ & $\begin{array}{c}841 \\
(309)\end{array}$ \\
\hline \# Municípios & 4813 & 4811 & 4804 & 4718 & 4714 & 4712 & 4751 & 4721 & 4724 & 4688 \\
\hline
\end{tabular}

Fonte: IBGE, FINBRA, ANP, DATASUS, RAIS/MTE e FIRJAN. Elaboração própria. Dados em valores reais calculados a partir do IPCA de 2016. Desvio Padrão entre parêntesis.

\section{RESULTADOS}

O primeiro passo do método Duplo Robusto é a estimação do propensity score. Conforme descrito no Capítulo 3, estima-se um modelo logit visando mensurar a probabilidade de receber o tratamento (rendas do petróleo), condicional às características observadas das municipalidades, tal qual descrito na equação (1). Seguindo os trabalhos de Carnicelli e Postali (2012, 2014), utilizam-se as seguintes covariadas municipais: população, parcela do PIB agrícola no PIB total (proxy para o inverso do grau de urbanização), receitas de transferências de recursos federais e estaduais per capita (livre de royalties do petróleo), demais receitas orçamentárias per capita (livre de transferências e de royalties do petróleo), 
controles de localização (latitude, longitude, altitude, área do município, dummies de região, dummies de coordenadas geográficas e interações, dummy de litoral) e dummies de ano.

É natural assumir que o recebimento de royalties seja primordialmente relacionado à controles geográficos. No entanto, para fins de balanceamento, ou seja, de moderação de diferenças nas covariadas entre os grupos de tratamento e controle, optou-se por acrescentar outros controles relacionados ao orçamento e ao nível de urbanização dos municípios, os quais podem influir na exploração econômica de petróleo. Os resultados da estimação do modelo logit são ilustrados na Tabela 6.

\section{Tabela 6 - Probabilidade Condicional de Tratamento - Modelo LOGIT}

\begin{tabular}{lc}
\hline & \\
População (em log) & $0.447^{* * *}$ \\
& $(0.0206)$ \\
PIB Agrícola / PIB & $0.798^{* * *}$ \\
& $(0.158)$ \\
Receita de Transferências Ex-Royalties per capita (em log) & $0.787 * * *$ \\
& $(0.0590)$ \\
Demais Receitas Orçamentárias (Ex-Royalties e Transferências) per capita (em log) & $0.168^{* * *}$ \\
& $(0.0149)$ \\
Litoral (dummy) & $-0.210^{* * *}$ \\
& $(0.0608)$ \\
Área do Município (em log) & $-0.0945^{* * *}$ \\
Latitude & $(0.0198)$ \\
Longitude & $-0.183^{* * *}$ \\
Altitude & $(0.00616)$ \\
& $0.122^{* * *}$ \\
Constante & $(0.00835)$ \\
& $-0.00166^{* * *}$ \\
Dumservações & $(7.44 \mathrm{e}-05)$ \\
Dummies de Ano & $-7.782^{* * *}$ \\
Dummies de Região & $(0.645)$ \\
\hline
\end{tabular}

Fonte: Elaboração própria. Dados em valores reais calculados a partir do IPCA 2016. Des vio padrão entre parênteses. (***) Significativo a $1 \% ;(* *)$ Significativo a $5 \% ;(*)$ Significativo a $10 \%$.

É importante esclarecer que, geralmente, o modelo logit é calculado com base em dados pré-tratamento, no caso, anteriores às transferências de royalties do petróleo. No entanto, dada a natureza volátil e incerta de seu recebimento, muitos municípios apresentam 
períodos com valores positivos e zero no período considerado. Sendo assim, cada localidade terá um propensity score diferente em cada instante de tempo.

A Figura 4 retrata o histograma com os propensity scores estimados para cada municipalidade. A partir da análise gráfica, nota-se mais uma vez a existência de uma grande assimetria na distribuição das rendas do petróleo entre os municípios brasileiros.

\section{Figura 4 - Histograma de Propensity Score dos Municípios}

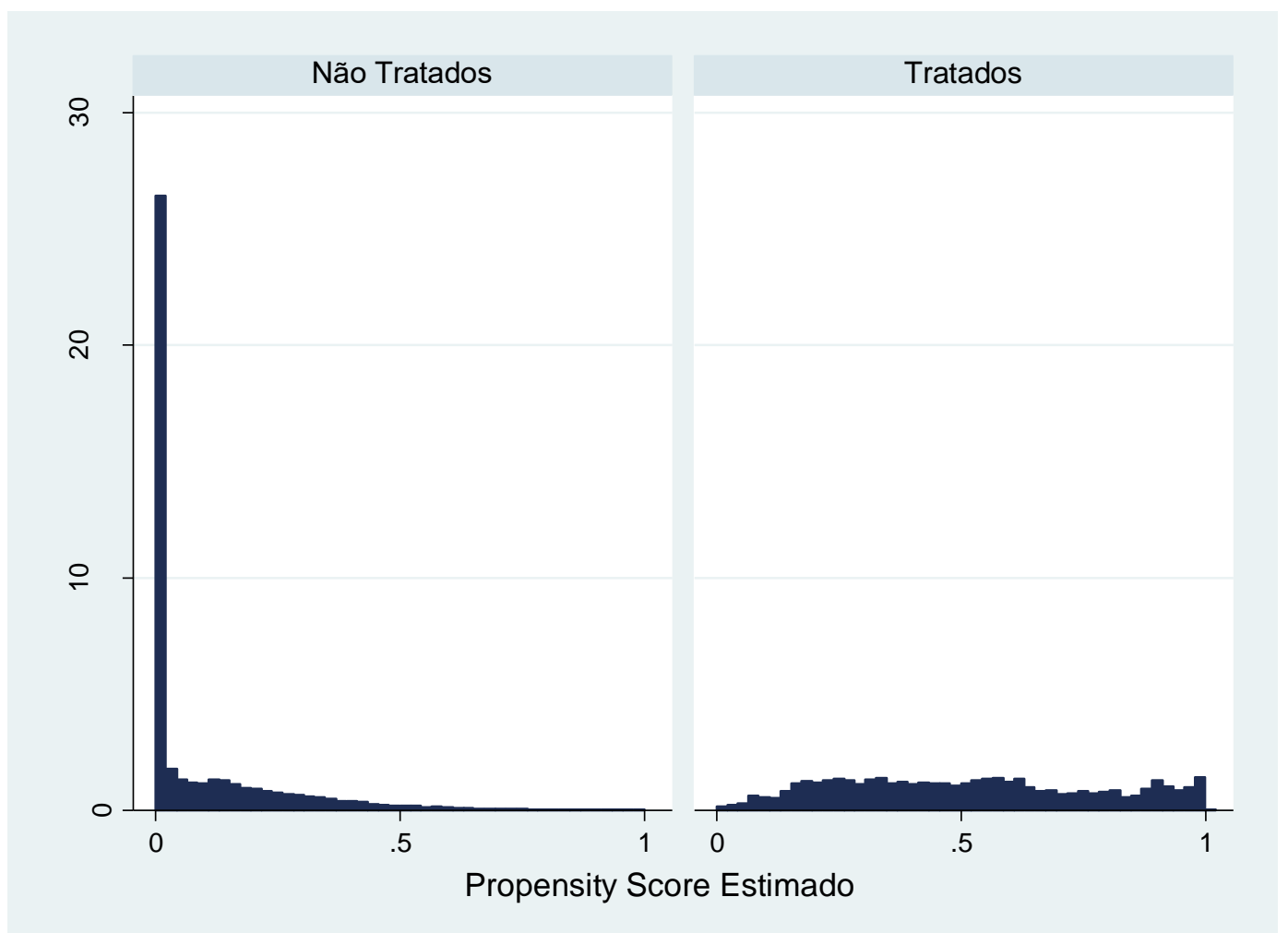

Fonte: Elaboração própria.

Por conta disso, com a finalidade de aprimorar a comparabilidade entre os municípios (assegurar a existência de um conjunto de municípios comparáveis), bem como reduzir a possibilidade viés dos estimadores do modelo do $2^{\circ}$ estágio (decorrente da assimetria na distribuição do propensity score), adota-se o procedimento de Galiani et al (2005) para criação de um suporte comum. No caso, definem-se os limites amostrais ao excluir as observações com scores inferiores (superiores) ao propensity score do município pertencente ao $1^{\circ}$ percentil $\left(99^{\circ}\right.$ percentil) do grupo de tratamento (controle). Segundo Dehejia e Wahba (1999), essa criação de suporte comum via propensity score gera estimadores eficientes. A Figura 5 ilustra a distribuição dos propensity scores no suporte comum após esse processo. 
Figura 5 - Histograma de Propensity Score no Suporte Comum

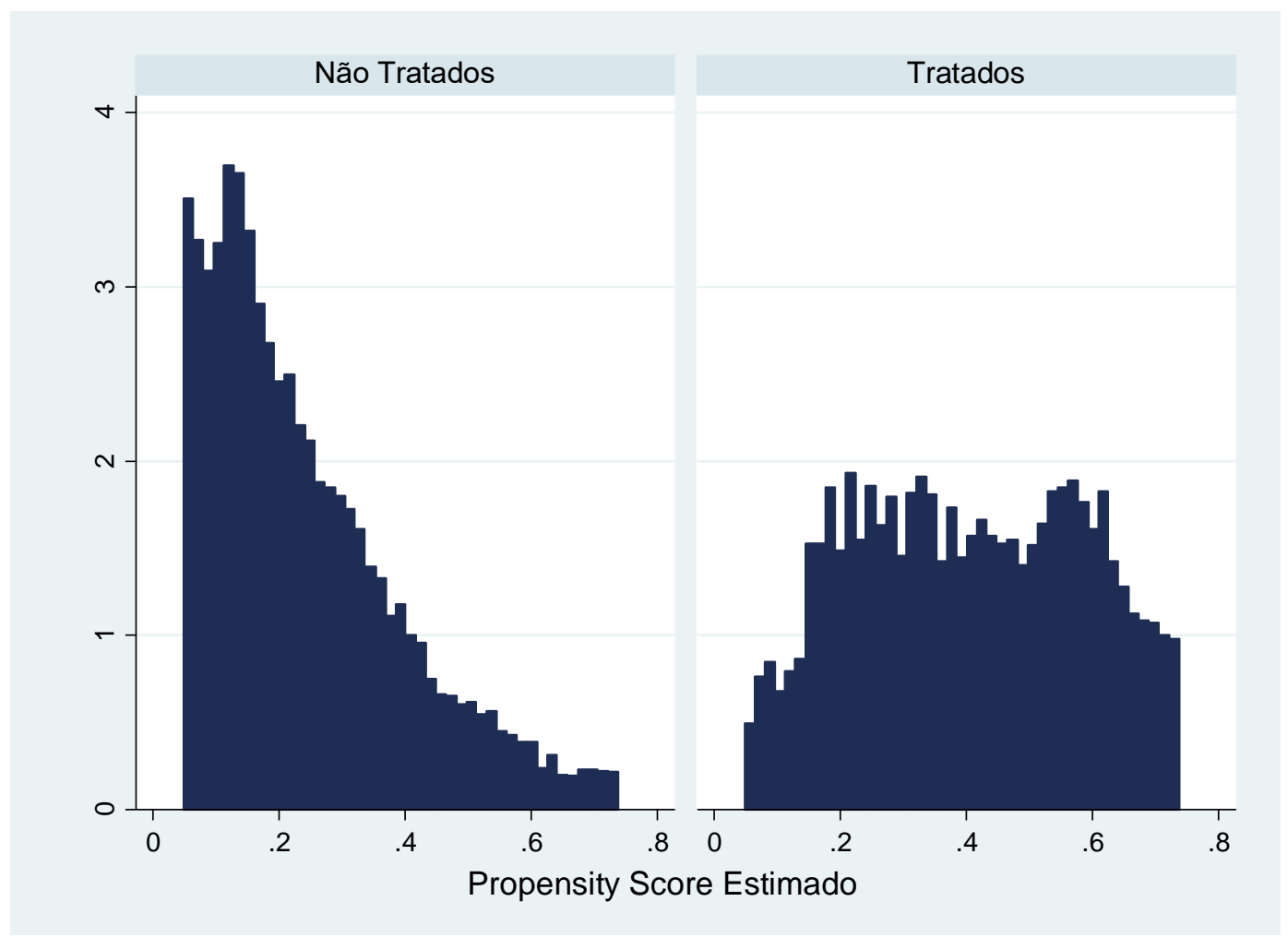

Fonte: Elaboração própria.

O passo seguinte é verificar se a primeira etapa do Duplo Robusto foi bemsucedida, ou seja, se houve o balanceamento das variáveis de interesse. Em vista disso, a Tabela 7 apresenta os testes de médias (t-Student) das variáveis independentes sob três circunstâncias: sem quaisquer correções; somente com observações pertencentes ao suporte comum; e, finalmente, condicionado ao propensity score estimado e ao suporte comum. A hipótese nula dos testes é de igualdade entre as médias dos grupos de tratamento e controle. Em relação aos dados exibidos, optou-se pela inclusão tanto das variáveis de controle do modelo do $2^{\circ}$ estágio - PIB, população, óbitos de crianças (menores de 4 anos de idade) por causas evitáveis e trabalhadores formais com ensino superior completo, receitas correntes e de transferências, IFDM Educação e Saúde - quanto de variáveis que serão utilizadas, no próximo capítulo, em discussão de royalties, gasto público e desenvolvimento. Sobre os resultados de interesse imediato, estatisticamente, não foi possível eliminar as diferenças nas médias apenas das variáveis IFDM Educação e receitas de transferências; para as demais, a hipótese de igualdade entre as médias não é rejeitada, de tal forma que o balanceamento efetuado pode ser considerado bem-sucedido. 
Tabela 7 - Balanceamento das Variáveis - Teste da Diferença de Médias

\begin{tabular}{|c|c|c|c|}
\hline Variável & Sem Correção & Suporte Comum & $\begin{array}{l}\text { Suporte Comum e } \\
\text { Propensity Score }\end{array}$ \\
\hline PIB per capita (em log) & $\begin{array}{c}-0.183 * * * \\
(0.00736)\end{array}$ & $\begin{array}{c}0.134 * * * \\
(0.0112)\end{array}$ & $\begin{array}{c}0.0162 \\
(0.0122)\end{array}$ \\
\hline PIB Ex-Industrial per capita (em log) & $\begin{array}{c}-0.229 * * * \\
(0.00659)\end{array}$ & $\begin{array}{c}0.0779 * * * \\
(0.00975)\end{array}$ & $\begin{array}{c}-0.0231 * * \\
(0.0106)\end{array}$ \\
\hline População & $\begin{array}{c}51,768 * * * \\
(1,935)\end{array}$ & $\begin{array}{c}15,509 * * * \\
(1,919)\end{array}$ & $\begin{array}{c}64.17 \\
(2,089)\end{array}$ \\
\hline Óbitos Evitáveis de Crianças (por 100 mil habitantes) & $\begin{array}{c}0.684 * * \\
(0.300)\end{array}$ & $\begin{array}{c}0.146 \\
(0.442)\end{array}$ & $\begin{array}{c}0.368 \\
(0.485)\end{array}$ \\
\hline Trab. Formais com Superior Completo (por 100 mil habitantes) & $\begin{array}{l}-18.32 \\
(24.12)\end{array}$ & $\begin{array}{c}46.88 \\
(51.19)\end{array}$ & $\begin{array}{l}-89.37 \\
(57.57)\end{array}$ \\
\hline Receitas Correntes Ex-Royalties per capita (em log) & $\begin{array}{c}-0.112 * * * \\
(0.00568)\end{array}$ & $\begin{array}{c}0.0364 * * * \\
(0.00727)\end{array}$ & $\begin{array}{c}-0.0115 \\
(0.00793)\end{array}$ \\
\hline Receita de Transferências Ex-Royalties per capita (em log) & $\begin{array}{c}-0.146 * * * \\
(0.00535)\end{array}$ & $\begin{array}{c}0.0111 \\
(0.00705)\end{array}$ & $\begin{array}{c}-0.0160^{* *} \\
(0.00772)\end{array}$ \\
\hline Receita Tributária per capita (em log) & $\begin{array}{c}-0.0441 * * * \\
(0.0113)\end{array}$ & $\begin{array}{c}0.208 * * * \\
(0.0191)\end{array}$ & $\begin{array}{c}0.0120 \\
(0.0207)\end{array}$ \\
\hline Despesa com Investimento per capita (em log) & $\begin{array}{c}-0.240 * * * \\
(0.00953)\end{array}$ & $\begin{array}{c}-0.0453 * * * \\
(0.0134)\end{array}$ & $\begin{array}{l}0.00170 \\
(0.0146)\end{array}$ \\
\hline Despesa com Pessoal per capita (em log) & $\begin{array}{c}-0.0295 * * * \\
(0.00552)\end{array}$ & $\begin{array}{c}0.0632 * * * \\
(0.00724)\end{array}$ & $\begin{array}{c}0.00463 \\
(0.00788)\end{array}$ \\
\hline Despesa com Educação e Cultura per capita (em log) & $\begin{array}{c}0.0577 * * * \\
(0.00550)\end{array}$ & $\begin{array}{c}0.0830 * * * \\
(0.00851)\end{array}$ & $\begin{array}{c}0.0813 * * * \\
(0.00951)\end{array}$ \\
\hline Despesa com Saúde e Saneamento per capita (em log) & $\begin{array}{c}-0.118 * * * \\
(0.00688)\end{array}$ & $\begin{array}{c}-0.0326 * * * \\
(0.00984)\end{array}$ & $\begin{array}{c}-0.0570 * * * \\
(0.0110)\end{array}$ \\
\hline Receita Orçamentária / Despesa Orçamentária & $\begin{array}{l}-0.997 \\
(2.310)\end{array}$ & $\begin{array}{c}0.0117 * \\
(0.00683)\end{array}$ & $\begin{array}{c}0.0113 \\
(0.00749)\end{array}$ \\
\hline IFDM Emprego e Renda (relativo à média nacional) & $\begin{array}{c}0.0144 * * * \\
(0.00383)\end{array}$ & $\begin{array}{c}0.0411 * * * \\
(0.00617)\end{array}$ & $\begin{array}{c}-0.0103 \\
(0.00685)\end{array}$ \\
\hline IFDM Saúde (relativo à média nacional) & $\begin{array}{c}-0.0793 * * * \\
(0.00333)\end{array}$ & $\begin{array}{l}0.00967 * \\
(0.00508)\end{array}$ & $\begin{array}{l}-0.00162 \\
(0.00570)\end{array}$ \\
\hline IFDM Educação (relativo à média nacional) & $\begin{array}{c}-0.0890 * * * \\
(0.00292)\end{array}$ & $\begin{array}{l}-0.00136 \\
(0.00422)\end{array}$ & $\begin{array}{c}0.0415 * * * \\
(0.00466)\end{array}$ \\
\hline
\end{tabular}

Fonte: Elaboração própria. Diferença de médias entre os grupos de tratamento e controle. Dados em valores reais calculados a partir do IPCA de 2016. Desvio padrão entre parênteses. (***) Significativo a 1\%; (**) Significativo a 5\%; (*) Significativo a $10 \%$.

A partir disso, parte-se para o $2^{\circ}$ estágio do Duplo Robusto, a estimação do modelo em painel de efeitos fixos ${ }^{19}$ apresentado na equação (2). Com base no método descrito no Capítulo 3, as variáveis independentes do modelo de efeitos fixos são ponderadas pelo propensity score estimado visando obter o ATT, isto é, o efeito médio do recebimento de royalties sobre os municípios beneficiados. Em decorrência dessa ponderação, as estimativas obtidas não podem ser interpretadas como efeitos marginais, sendo assim, são os sinais dos coeficientes estimados e sua significância que assumem particular importância. Nesta etapa,

${ }^{19} \mathrm{O}$ Teste de Hausman foi realizado, conforme as especificações utilizadas, e corroborou o uso do modelo em painel de efeitos fixos em detrimento da abordagem por efeitos aleatórios. 
conforme mencionado acima, utilizam-se as seguintes variáveis de controle: PIB per capita do período anterior (controle para o nível de desenvolvimento do município) ${ }^{20}$, população municipal (controle para o tamanho da cidade), receitas correntes e de transferências per capita (controle para a disponibilidade de recursos), número de óbitos de crianças por causas evitáveis (controle para a qualidade de vida das municipalidades) e número de trabalhadores formais com ensino superior completo (controle para o nível de qualificação do capital humano local).

Todas as estimações apresentadas têm como variável dependente a taxa de crescimento real do PIB per capita municipal ${ }^{21}$, sendo que, em cada modelo, sob diferentes especificações, colocaram-se lado a lado os resultados da estimação de painel simples de efeitos fixos considerando toda a amostra e os da análise do ATT restrita aos municípios tratados que pertencem ao suporte comum. Acerca das três especificações utilizadas em cada modelo, enquanto a primeira busca explicar o efeito dos royalties ${ }^{22}$ sobre o crescimento, controlando pelo PIB defasado, população, óbitos evitáveis de crianças e trabalhadores formais com superior completo, as duas seguintes incorporam as receitas com transferências e as receitas correntes, respectivamente. Isso é uma forma de assegurar que o coeficiente estimado para os royalties do petróleo (que fazem parte de receitas oriundas de transferências) não incorpore os efeitos de outras variáveis de receitas do orçamento, reduzindo a possibilidade de obtenção de estimadores enviesados. Em adição, a inclusão de dummy de ano visa captar os movimentos da economia como um todo.

Nas Tabelas 8, 9 e 10 foram estimados modelos com variáveis contemporâneas, defasadas, e contemporâneas e defasadas, respectivamente. O objetivo de tal análise é verificar a sensibilidade dos resultados à diferentes especificações, sendo que o uso de controles defasados tem a finalidade capturar a persistência temporal dos efeitos de certas variáveis no crescimento dos municípios. Ademais, é importante esclarecer que o uso de

\footnotetext{
${ }^{20}$ Ademais, a inclusão do PIB per capita defasado se justifica pela ideia de convergência condicional entre os municípios, na qual um PIB mais alto no instante anterior potencialmente gera uma taxa de crescimento menor no período analisado.

${ }^{21}$ A taxa de crescimento anual do PIB per capita foi calculada a partir da diferença entre o log dos produtos municipais. Em vista disso, caso fosse utilizado o PIB per capita como variável dependente e fosse mantido o PIB per capita defasado como variável de controle, os resultados seriam análogos, com exceção do sinal e da magnitude do coeficiente estimado deste controle. No entanto, a opção do estudo para o crescimento permite a comparação com a literatura existente. Além disso, em relação à observação de Alexeev e Conrad (2009) mencionada no Capítulo 2, o período relativamente curto de análise minimiza a obtenção de resultados prejudicados por esgotamentos de campos petrolíferos.

${ }^{22}$ Para efeito de ajuste na base de dados, a variável independente de royalties do petróleo foi inserida, no modelo do $2^{\circ}$ estágio, como o ln de 1 acrescido do valor anual de royalties per capita, uma vez que os municípios não beneficiários têm valor igual a zero. Desse modo, assume-se $\ln (x) \approx \ln (1+x)$.
} 
apenas uma defasagem (quando aplicável) se deve à limitação em termos de tamanho amostral.

Tabela 8 - Estimação com Variáveis Contemporâneas

\begin{tabular}{|c|c|c|c|c|c|c|}
\hline \multirow{2}{*}{ Taxa de Crescimento do PIB per capita (anual) } & \multicolumn{3}{|c|}{ Efeitos Fixos } & \multicolumn{3}{|c|}{ ATT } \\
\hline & 1 & 2 & 3 & 1 & 2 & 3 \\
\hline Royalties per capita (em log) & $\begin{array}{l}0.0193 * * \\
(0.00784)\end{array}$ & $\begin{array}{l}0.0172^{* *} \\
(0.00788)\end{array}$ & $\begin{array}{l}0.0180 * * \\
(0.00796)\end{array}$ & $\begin{array}{c}0.0186 \\
(0.0148)\end{array}$ & $\begin{array}{c}0.0199 \\
(0.0148)\end{array}$ & $\begin{array}{c}0.0203 \\
(0.0148)\end{array}$ \\
\hline Lag PIB per capita (em log) & $\begin{array}{c}-0.458 * * * \\
(0.0138)\end{array}$ & $\begin{array}{c}-0.474 * * * \\
(0.0124)\end{array}$ & $\begin{array}{c}-0.466 * * * \\
(0.0124)\end{array}$ & $\begin{array}{c}-1,963 * * * \\
(131.3)\end{array}$ & $\begin{array}{c}-1,994 * * * * \\
(132.9)\end{array}$ & $\begin{array}{c}-1,989^{* * * *} \\
(133.2)\end{array}$ \\
\hline População (em log) & $\begin{array}{c}-0.375 * * * \\
(0.0196)\end{array}$ & $\begin{array}{c}-0.313^{* * * *} \\
(0.0223)\end{array}$ & $\begin{array}{c}-0.377 * * * \\
(0.0198)\end{array}$ & $\begin{array}{c}-1,977^{* * * *} \\
(270.3)\end{array}$ & $\begin{array}{c}-1,674 * * * \\
(287.0)\end{array}$ & $\begin{array}{c}-1,678^{* * * *} \\
(276.0)\end{array}$ \\
\hline Trab. Formais com Superior Completo (por 100 mil habitantes) & $\begin{array}{c}3.21 \mathrm{e}-06 \\
(2.66 \mathrm{e}-06)\end{array}$ & $\begin{array}{l}3.40 \mathrm{e}-06 \\
(2.74 \mathrm{e}-06)\end{array}$ & $\begin{array}{c}3.51 \mathrm{e}-06 \\
(2.84 \mathrm{e}-06)\end{array}$ & $\begin{array}{c}0.0207 \\
(0.0290)\end{array}$ & $\begin{array}{c}0.0173 \\
(0.0287)\end{array}$ & $\begin{array}{c}0.0156 \\
(0.0288)\end{array}$ \\
\hline Óbitos Evitáveis de Crianças (por 100 mil habitantes) & $\begin{array}{c}0.000177 * * * \\
(5.67 \mathrm{e}-05)\end{array}$ & $\begin{array}{c}0.000197 * * * \\
(5.76 \mathrm{e}-05)\end{array}$ & $\begin{array}{c}0.000193 * * * \\
(5.80 \mathrm{e}-05)\end{array}$ & $\begin{array}{l}1.571 \\
(1.051)\end{array}$ & $\begin{array}{l}1.458 \\
(1.048)\end{array}$ & $\begin{array}{l}1.411 \\
(1.042)\end{array}$ \\
\hline Receita de Transf. (ex-royalties) per capita (em log) & & $\begin{array}{c}0.107 * * * \\
(0.0161)\end{array}$ & & & $\begin{array}{c}455.3 * * * \\
(175.4)\end{array}$ & \\
\hline Receita Corrente (ex-royalties) per capita (em log) & & & $\begin{array}{c}0.0154 * * * * \\
(0.00544)\end{array}$ & & & $\begin{array}{c}445.5^{* * * *} \\
(151.5)\end{array}$ \\
\hline Constante & $\begin{array}{c}8.063 * * * \\
(0.261)\end{array}$ & $\begin{array}{c}6.789 * * * \\
(0.338)\end{array}$ & $\begin{array}{c}8.043^{* * * *} \\
(0.268)\end{array}$ & $\begin{array}{c}9.314 * * * \\
(0.822)\end{array}$ & $\begin{array}{c}7.799 * * * \\
(0.980)\end{array}$ & $\begin{array}{c}7.802 * * * \\
(0.918)\end{array}$ \\
\hline \# Observações & 36,078 & 35,074 & 35,096 & 3,164 & 3,164 & 3,164 \\
\hline Suporte Comum & NÃO & NÃO & NÃO & SIM & SIM & SIM \\
\hline R-Quadrado & 0.243 & 0.252 & 0.247 & 0.300 & 0.304 & 0.303 \\
\hline \# Municípios & 5,519 & 5,512 & 5,512 & 697 & 697 & 697 \\
\hline Dummy Ano & SIM & SIM & SIM & SIM & SIM & SIM \\
\hline
\end{tabular}

Fonte: Elaboração própria. Dados em valores reais calculados a partir do IPCA 2016. Desvio padrão robusto entre parêntesis. $\left.{ }^{* * *}\right)$ Significativo a $1 \%,\left({ }^{* *}\right)$ Significativo a $5 \%,(*)$ Significativo a $10 \%$.

Tabela 9 - Estimação com Variáveis Defasadas

\begin{tabular}{|c|c|c|c|c|c|c|}
\hline \multirow{2}{*}{ Taxa de Crescimento do PIB per capita (anual) } & \multicolumn{3}{|c|}{ Efeitos Fixos } & \multicolumn{3}{|c|}{ ATT } \\
\hline & 1 & 2 & 3 & 1 & 2 & 3 \\
\hline Lag Royalties per capita (em log) & $\begin{array}{c}0.00777 \\
(0.00637)\end{array}$ & $\begin{array}{c}0.00758 \\
(0.00655)\end{array}$ & $\begin{array}{c}0.00827 \\
(0.00654)\end{array}$ & $\begin{array}{c}0.00533 \\
(0.00877)\end{array}$ & $\begin{array}{c}0.00541 \\
(0.00887)\end{array}$ & $\begin{array}{c}0.00516 \\
(0.00891)\end{array}$ \\
\hline Lag PIB per capita (em log) & $\begin{array}{c}-0.479 * * * \\
(0.0157)\end{array}$ & $\begin{array}{c}-0.494 * * * \\
(0.0136)\end{array}$ & $\begin{array}{c}-0.493 * * * \\
(0.0136)\end{array}$ & $\begin{array}{c}-1,794 * * * \\
(191.1)\end{array}$ & $\begin{array}{c}-1,813 * * * \\
(197.5)\end{array}$ & $\begin{array}{c}-1,810^{* * * *} \\
(197.4)\end{array}$ \\
\hline Lag População (em log) & $\begin{array}{c}0.266 * * * * \\
(0.0197)\end{array}$ & $\begin{array}{c}0.306 * * * \\
(0.0236)\end{array}$ & $\begin{array}{c}0.305 * * * \\
(0.0226)\end{array}$ & $\begin{array}{c}1,552^{* * * * *} \\
(313.9)\end{array}$ & $\begin{array}{c}1,384 * * * \\
(320.5)\end{array}$ & $\begin{array}{c}1,330 * * * \\
(325.9)\end{array}$ \\
\hline Lag Trab. Formais com Superior Completo (por 100 mil habitantes) & $\begin{array}{c}8.33 \mathrm{e}-07 \\
(3.46 \mathrm{e}-06)\end{array}$ & $\begin{array}{c}2.91 \mathrm{e}-06 \\
(3.09 \mathrm{e}-06)\end{array}$ & $\begin{array}{c}2.78 \mathrm{e}-06 \\
(3.07 \mathrm{e}-06)\end{array}$ & $\begin{array}{c}-0.00133 \\
(0.0273)\end{array}$ & $\begin{array}{c}0.0135 \\
(0.0232)\end{array}$ & $\begin{array}{c}0.0159 \\
(0.0230)\end{array}$ \\
\hline Lag Óbitos Evitáveis de Crianças (por 100 mil habitantes) & $\begin{array}{l}-2.04 \mathrm{e}-05 \\
(5.65 \mathrm{e}-05)\end{array}$ & $\begin{array}{l}-1.42 \mathrm{e}-05 \\
(5.73 \mathrm{e}-05)\end{array}$ & $\begin{array}{l}-1.41 \mathrm{e}-05 \\
(5.73 \mathrm{e}-05)\end{array}$ & $\begin{array}{l}-1.235 \\
(0.971)\end{array}$ & $\begin{array}{l}-1.071 \\
(1.009)\end{array}$ & $\begin{array}{l}-1.068 \\
(1.011)\end{array}$ \\
\hline Lag Receita de Transf. (ex-royalties) per capita (em log) & & $\begin{array}{c}0.0457^{* * * *} \\
(0.0132)\end{array}$ & & & $\begin{array}{l}-190.8 \\
(128.2)\end{array}$ & \\
\hline Lag Receita Corrente (ex-royalties) per capita (em log) & & & $\begin{array}{c}0.0437 * * * * \\
(0.0125)\end{array}$ & & & $\begin{array}{c}-267.3 * * \\
(134.1)\end{array}$ \\
\hline Constante & $\begin{array}{c}2.068 * * * \\
(0.290)\end{array}$ & $\begin{array}{c}1.460^{* * * *} \\
(0.357)\end{array}$ & $\begin{array}{c}1.467 * * * * \\
(0.340)\end{array}$ & $\begin{array}{c}0.337 \\
(1.050)\end{array}$ & $\begin{array}{c}1.133 \\
(1.098)\end{array}$ & $\begin{array}{l}1.407 \\
(1.116)\end{array}$ \\
\hline \# Observações & 31,650 & 30,936 & 30,946 & 2,803 & 2,743 & 2,745 \\
\hline Suporte Comum & NÃO & NÃO & NÃO & SIM & SIM & SIM \\
\hline R-Quadrado & 0.277 & 0.285 & 0.286 & 0.316 & 0.321 & 0.321 \\
\hline \# Municípios & 5,503 & 5,494 & 5,494 & 685 & 674 & 674 \\
\hline Dummy Ano & SIM & SIM & SIM & SIM & SIM & SIM \\
\hline
\end{tabular}

Fonte: Elaboração própria. Dados em valores reais calculados a partir do IPCA 2016. Desvio padrão robusto entre parêntesis. (***) Significativo a $1 \%,(* *)$ Significativo a $5 \%,(*)$ Significativo a $10 \%$. 
Tabela 10 - Estimação com Variáveis Defasadas e Contemporâneas

\begin{tabular}{|c|c|c|c|c|c|c|}
\hline \multirow{2}{*}{ Taxa de Crescimento do PIB per capita (anual) } & \multicolumn{3}{|c|}{ Efeitos Fixos } & \multicolumn{3}{|c|}{ ATT } \\
\hline & 1 & 2 & 3 & 1 & 2 & 3 \\
\hline Lag Royalties per capita (em log) & $\begin{array}{l}-0.00731 \\
(0.00633)\end{array}$ & $\begin{array}{l}-0.00824 \\
(0.00671)\end{array}$ & $\begin{array}{l}-0.00820 \\
(0.00664)\end{array}$ & $\begin{array}{c}-0.00875 \\
(0.0105)\end{array}$ & $\begin{array}{c}-0.00825 \\
(0.0105)\end{array}$ & $\begin{array}{r}-0.00850 \\
(0.0106)\end{array}$ \\
\hline Royalties per capita (em log) & $\begin{array}{c}0.0251 * * * \\
(0.00785)\end{array}$ & $\begin{array}{c}0.0242 * * * \\
(0.00773)\end{array}$ & $\begin{array}{c}0.0256 * * * \\
(0.00796)\end{array}$ & $\begin{array}{c}0.0216 \\
(0.0137)\end{array}$ & $\begin{array}{c}0.0224 \\
(0.0139)\end{array}$ & $\begin{array}{c}0.0225 \\
(0.0139)\end{array}$ \\
\hline Lag PIB per capita (em log) & $\begin{array}{c}-0.460 * * * \\
(0.0165)\end{array}$ & $\begin{array}{c}-0.485^{* * * *} \\
(0.0136)\end{array}$ & $\begin{array}{c}-0.479 * * * \\
(0.0135)\end{array}$ & $\begin{array}{c}-1,957 * * * \\
(137.9)\end{array}$ & $\begin{array}{c}-2,033 * * * \\
(131.2)\end{array}$ & $\begin{array}{c}-2,025 * * * * \\
(130.5)\end{array}$ \\
\hline Lag População (em log) & $\begin{array}{c}0.526 * * * \\
(0.0218)\end{array}$ & $\begin{array}{c}0.536 * * * \\
(0.0238)\end{array}$ & $\begin{array}{c}0.556 * * * \\
(0.0241)\end{array}$ & $\begin{array}{c}2,649 * * * \\
(353.5)\end{array}$ & $\begin{array}{c}2,402 * * * * \\
(407.6)\end{array}$ & $\begin{array}{c}2,270 * * * \\
(405.5)\end{array}$ \\
\hline População (em log) & $\begin{array}{c}-0.643 * * * \\
(0.0410)\end{array}$ & $\begin{array}{c}-0.591 * * * \\
(0.0432)\end{array}$ & $\begin{array}{c}-0.648^{* * * *} \\
(0.0420)\end{array}$ & $\begin{array}{c}-3,671^{* * * *} \\
(605.4)\end{array}$ & $\begin{array}{c}-3,393 * * * \\
(656.1)\end{array}$ & $\begin{array}{c}-3,287 * * * * \\
(638.1)\end{array}$ \\
\hline Lag Trab. Formais com Superior Completo (por 100 mil habitantes) & $\begin{array}{c}3.78 \mathrm{e}-06 \\
(3.49 \mathrm{e}-06)\end{array}$ & $\begin{array}{l}5.51 \mathrm{e}-06^{*} \\
(3.18 \mathrm{e}-06)\end{array}$ & $\begin{array}{l}5.63 \mathrm{e}-06^{*} \\
(3.18 \mathrm{e}-06)\end{array}$ & $\begin{array}{l}-0.0214 \\
(0.0302)\end{array}$ & $\begin{array}{l}-0.0112 \\
(0.0256)\end{array}$ & $\begin{array}{l}-0.0110 \\
(0.0255)\end{array}$ \\
\hline Trab. Formais com Superior Completo (por 100 mil habitantes) & $\begin{array}{c}1.18 \mathrm{e}-06 \\
(1.15 \mathrm{e}-06)\end{array}$ & $\begin{array}{c}1.51 \mathrm{e}-06 \\
(1.27 \mathrm{e}-06)\end{array}$ & $\begin{array}{c}1.51 \mathrm{e}-06 \\
(1.27 \mathrm{e}-06)\end{array}$ & $\begin{array}{c}0.0602 * * \\
(0.0246)\end{array}$ & $\begin{array}{c}0.0621 * * \\
(0.0260)\end{array}$ & $\begin{array}{c}0.0612 * * \\
(0.0258)\end{array}$ \\
\hline Lag Óbitos Evitáveis de Crianças (por 100 mil habitantes) & $\begin{array}{c}6.41 \mathrm{e}-05 \\
(5.92 \mathrm{e}-05)\end{array}$ & $\begin{array}{c}5.88 \mathrm{e}-05 \\
(6.08 \mathrm{e}-05)\end{array}$ & $\begin{array}{c}6.77 \mathrm{e}-05 \\
(6.09 \mathrm{e}-05)\end{array}$ & $\begin{array}{l}-0.873 \\
(1.011)\end{array}$ & $\begin{array}{l}-0.539 \\
(1.031)\end{array}$ & $\begin{array}{l}-0.506 \\
(1.032)\end{array}$ \\
\hline Óbitos Evitáveis de Crianças (por 100 mil habitantes) & $\begin{array}{l}0.000113^{*} \\
(6.82 \mathrm{e}-05)\end{array}$ & $\begin{array}{c}0.000142 * * \\
(7.11 \mathrm{e}-05)\end{array}$ & $\begin{array}{l}0.000134^{*} \\
(7.13 \mathrm{e}-05)\end{array}$ & $\begin{array}{c}1.134 \\
(1.266)\end{array}$ & $\begin{array}{c}1.298 \\
(1.269)\end{array}$ & $\begin{array}{l}1.190 \\
(1.256)\end{array}$ \\
\hline Lag Receita de Transf. (ex-royalties) per capita (em log) & & $\begin{array}{c}0.0517 * * * \\
(0.0108)\end{array}$ & & & $\begin{array}{l}-87.37 \\
(184.5)\end{array}$ & \\
\hline Receita de Transf. (ex-royalties) per capita (em log) & & $\begin{array}{c}0.0728^{* * *} \\
(0.0146)\end{array}$ & & & $\begin{array}{c}324.6 \\
(226.7)\end{array}$ & \\
\hline Lag Receita Corrente (ex-royalties) per capita (em log) & & & $\begin{array}{c}0.0516 * * * * \\
(0.0126)\end{array}$ & & & $\begin{array}{l}-218.5 \\
(147.8)\end{array}$ \\
\hline Receita Corrente (ex-royalties) per capita (em log) & & & $\begin{array}{l}0.0113 * * \\
(0.00454)\end{array}$ & & & $\begin{array}{c}412.7 * * * \\
(131.8)\end{array}$ \\
\hline Constante & $\begin{array}{c}5.602 * * * \\
(0.380)\end{array}$ & $\begin{array}{c}4.275^{* * * *} \\
(0.459)\end{array}$ & $\begin{array}{c}5.048 * * * \\
(0.414)\end{array}$ & $\begin{array}{c}7.003 * * * \\
(1.152)\end{array}$ & $\begin{array}{c}6.656^{* * * *} \\
(1.385)\end{array}$ & $\begin{array}{c}6.773 * * * \\
(1.298)\end{array}$ \\
\hline \# Observações & 27,723 & 26,514 & 26,538 & 2,674 & 2,620 & 2,622 \\
\hline Suporte Comum & NÃO & NÃO & NÃO & SIM & SIM & SIM \\
\hline R-Quadrado & 0.300 & 0.312 & 0.309 & 0.367 & 0.375 & 0.376 \\
\hline \# Municípios & 5,104 & 5,081 & 5,081 & 662 & 651 & 651 \\
\hline Dummy Ano & SIM & SIM & SIM & SIM & SIM & SIM \\
\hline
\end{tabular}

Fonte: Elaboração própria. Dados em valores reais calculados a partir do IPCA 2016. Desvio padrão robusto entre parêntesis. (***) Significativo a 1\%, $(* *)$ Significativo a $5 \%,(*)$ Significativo a 10\%.

A comparação dos modelos exibidos nas Tabelas de 8 a 10 mostra, no caso dos efeitos fixos, que existe uma relação positiva entre os royalties contemporâneos e o crescimento do PIB dos municípios. No entanto, ao proceder ao cálculo do ATT com limitação da amostra para suporte comum, observa-se que a relação entre os royalties (contemporâneo e defasado) e a taxa de crescimento não é estatisticamente diferente de zero.

Além disso, no modelo menos parcimonioso da Tabela 10, construído a partir da combinação de variáveis defasadas e contemporâneas, notam-se que as variáveis de população municipal e de PIB defasado apresentam sinais esperados e nível de significância de $1 \%$ em todas as especificações; analogamente, o controle para o nível de capital humano também tem efeito relevante e positivo com a evolução do PIB.

Com base nos resultados anteriores, foi proposto um modelo adicional, composto por algumas variáveis defasadas - PIB per capita, população e óbitos de crianças - além de outras contemporâneas - royalties, população, trabalhadores formais e demais receitas. Neste 
caso, apresentado na Tabela 11, mais uma vez a associação positiva entre royalties e PIB desapareceu com o método Duplamente Robusto. Em paralelo, estimou-se o mesmo modelo (ver Tabela 14 no Apêndice) tendo os IFDM de Educação e Saúde como controles (em substituição aos empregados formais com superior completo e óbitos evitáveis, respectivamente) e o resultado obtido foi semelhante.

Tabela 11 - Estimação com Variáveis Defasadas e Contemporâneas Selecionadas I

\begin{tabular}{|c|c|c|c|c|c|c|}
\hline \multirow{2}{*}{ Taxa de Crescimento do PIB per capita (anual) } & \multicolumn{3}{|c|}{ Efeitos Fixos } & \multicolumn{3}{|c|}{ ATT } \\
\hline & 1 & 2 & 3 & 1 & 2 & 3 \\
\hline Royalties per capita (em log) & $\begin{array}{c}0.0189 * * * \\
(0.00591)\end{array}$ & $\begin{array}{c}0.0169 * * * \\
(0.00578)\end{array}$ & $\begin{array}{c}0.0178 * * * \\
(0.00597)\end{array}$ & $\begin{array}{c}0.0111 \\
(0.00883)\end{array}$ & $\begin{array}{c}0.0118 \\
(0.00881)\end{array}$ & 0.0122 \\
\hline Lag PIB per capita (em log) & $\begin{array}{c}-0.426^{* * *} \\
(0.0136)\end{array}$ & $\begin{array}{c}-0.441 * * * \\
(0.0126)\end{array}$ & $\begin{array}{c}-0.435^{* * *} \\
(0.0126)\end{array}$ & $\begin{array}{c}-1,699 * * * \\
(175.2)\end{array}$ & $\begin{array}{c}-1,724 * * * \\
(179.2)\end{array}$ & $\begin{array}{c}-1,726 * * * * \\
(177.1)\end{array}$ \\
\hline Lag População (em log) & $\begin{array}{c}0.538 * * * \\
(0.0207)\end{array}$ & $\begin{array}{c}0.510 * * * * \\
(0.0210)\end{array}$ & $\begin{array}{c}0.528 * * * \\
(0.0206)\end{array}$ & $\begin{array}{c}2,923 * * * \\
(348.9)\end{array}$ & $\begin{array}{c}2,804 * * * * \\
(357.5)\end{array}$ & $\begin{array}{c}2,781 * * * \\
(355.9)\end{array}$ \\
\hline População (em log) & $\begin{array}{c}-0.778^{* * * *} \\
(0.0237)\end{array}$ & $\begin{array}{c}-0.711 * * * \\
(0.0273)\end{array}$ & $\begin{array}{c}-0.765^{* * * *} \\
(0.0235)\end{array}$ & $\begin{array}{c}-4,216^{* * * *} \\
(377.4)\end{array}$ & $\begin{array}{c}-3,918 * * * \\
(397.8)\end{array}$ & $\begin{array}{c}-3,860 * * * \\
(399.1)\end{array}$ \\
\hline Trab. Formais com Superior Completo (por 100 mil habitantes) & $\begin{array}{c}3.16 \mathrm{e}-06 \\
(2.37 \mathrm{e}-06)\end{array}$ & $\begin{array}{c}3.43 \mathrm{e}-06 \\
(2.52 \mathrm{e}-06)\end{array}$ & $\begin{array}{c}3.46 \mathrm{e}-06 \\
(2.55 \mathrm{e}-06)\end{array}$ & $\begin{array}{c}0.0195 \\
(0.0273)\end{array}$ & $\begin{array}{c}0.0185 \\
(0.0273)\end{array}$ & $\begin{array}{c}0.0165 \\
(0.0274)\end{array}$ \\
\hline Lag Óbitos Evitáveis de Crianças (por 100 mil habitantes) & $\begin{array}{c}3.74 \mathrm{e}-05 \\
(4.79 \mathrm{e}-05)\end{array}$ & $\begin{array}{c}3.40 \mathrm{e}-05 \\
(4.87 \mathrm{e}-05)\end{array}$ & $\begin{array}{c}4.07 \mathrm{e}-05 \\
(4.89 \mathrm{e}-05)\end{array}$ & $\begin{array}{l}-0.955 \\
(0.775)\end{array}$ & $\begin{array}{l}-0.992 \\
(0.777)\end{array}$ & $\begin{array}{l}-1.016 \\
(0.778)\end{array}$ \\
\hline Receita de Transf. (ex-royalties) per capita (em log) & & $\begin{array}{c}0.0726^{* * * *} \\
(0.0144)\end{array}$ & & & $\begin{array}{c}307.2^{* * *} \\
(141.9)\end{array}$ & \\
\hline Receita Corrente (ex-royalties) per capita (em log) & & & $\begin{array}{c}0.0126^{* * * *} \\
(0.00435)\end{array}$ & & & $\begin{array}{c}363.4 * * * \\
(127.8)\end{array}$ \\
\hline Constante & $\begin{array}{c}6.466 * * * \\
(0.265)\end{array}$ & $\begin{array}{c}5.668 * * * \\
(0.326)\end{array}$ & $\begin{array}{c}6.433 * * * \\
(0.274)\end{array}$ & $\begin{array}{c}7.091 * * * \\
(0.918)\end{array}$ & $\begin{array}{c}6.139 * * * * \\
(0.939)\end{array}$ & $\begin{array}{c}5.941 * * * \\
(0.983)\end{array}$ \\
\hline \# Observações & 36,342 & 35,325 & 35,345 & 3,177 & 3,177 & 3,177 \\
\hline Suporte Comum & NÃO & NÃO & NÃO & SIM & SIM & SIM \\
\hline R-Quadrado & 0.269 & 0.277 & 0.274 & 0.327 & 0.329 & 0.330 \\
\hline \# Municípios & 5,520 & 5,512 & 5,512 & 696 & 696 & 696 \\
\hline Dummy Ano & SIM & SIM & SIM & SIM & SIM & SIM \\
\hline
\end{tabular}

Fonte: Elaboração própria. Dados em valores reais calculados a partir do IPCA 2016. Desvio padrão robusto entre parêntesis. (***) Significativo a 1\%, (**) Significativo a $5 \%,(*)$ Significativo a $10 \%$.

Tendo em vista as evidências encontradas, existe a possibilidade de que a relação positiva entre rendas do petróleo e crescimento do PIB no modelo em efeitos fixos resulte de um viés causado pela metodologia de cálculo do PIB municipal (como visto, o IBGE utiliza justamente os royalties para estimar a contribuição de cada munícipio para a produção petrolífera estadual). Entretanto, mesmo diante dessa possibilidade e de possíveis externalidades positivas decorrentes da atividade petrolífera sobre outros setores industriais, o cálculo do efeito médio do recebimento de royalties sobre o crescimento do PIB dos municípios tratados não apresentou relação significante. Dessa maneira, é provável que o método Duplamente Robusto tenha contribuído para minimizar problemas de viés nos parâmetros, decorrentes da metodologia do IBGE e de variáveis omitidas.

Por outro lado, a fim de verificar o efeito da produção de petróleo no PIB dos municípios, o artigo de Monteiro e Ferraz (2010) propôs a utilização do PIB não industrial 
como variável dependente. Embora tal sugestão elimine o problema mencionado acima, ela incorre em um custo elevado, a exclusão de todas as atividades econômicas contabilizadas no PIB industrial, ou seja, restringe-se a análise apenas aos PIB de serviços e agropecuário. Mesmo assim, inspirado nessa proposição, o modelo da Tabela 11 foi recalculado tendo a taxa de crescimento do PIB não industrial como variável resposta. O resultado, apresentado na Tabela 12, indica que os royalties também não afetam o PIB não industrial. Em outras palavras, isso traz evidências de que o recebimento de rendas do petróleo não tem conexão com o PIB agropecuário e de serviços, o que pode ser explicado pelo fato de que a maior parte de sua produção ser realizada no mar.

Por conseguinte, o resultado obtido vai de encontro às evidências de MRN obtidas até então na literatura para recursos petrolíferos no Brasil (Postali, 2009; Monteiro e Ferraz, 2010) e nos EUA (Papyrakis e Gerlach, 2007; James e Aadland, 2011). É importante salientar que em todos os modelos construídos nesta dissertação a MRN é rejeitada e tampouco existe uma relação positiva significante entre os royalties e o crescimento das localidades.

Tabela 12 - Estimação com o PIB Ex-Indústria como Variável Dependente

\begin{tabular}{|c|c|c|c|c|c|c|}
\hline \multirow{2}{*}{ Taxa de Crescimento do PIB Ex-Ind. per capita (anual) } & \multicolumn{3}{|c|}{ Efeitos Fixos } & \multicolumn{3}{|c|}{ ATT } \\
\hline & 1 & 2 & 3 & 1 & 2 & 3 \\
\hline Royalties per capita (em log) & $\begin{array}{c}0.00815^{* * *} \\
(0.00405)\end{array}$ & $\begin{array}{l}0.00710^{*} \\
(0.00395)\end{array}$ & $\begin{array}{l}0.00750^{*} \\
(0.00409)\end{array}$ & $\begin{array}{c}-0.000153 \\
(0.00508)\end{array}$ & $\begin{array}{l}0.000220 \\
(0.00507)\end{array}$ & $\begin{array}{l}0.000525 \\
(0.00511)\end{array}$ \\
\hline Lag PIB Ex-Ind. per capita (em log) & $\begin{array}{c}-0.467 * * * \\
(0.0120)\end{array}$ & $\begin{array}{c}-0.479 * * * \\
(0.0119)\end{array}$ & $\begin{array}{c}-0.474^{* * * *} \\
(0.0117)\end{array}$ & $\begin{array}{c}-1,589 * * * \\
(135.4)\end{array}$ & $\begin{array}{c}-1,602 * * * \\
(135.8)\end{array}$ & $\begin{array}{c}-1,605 * * * * \\
(132.8)\end{array}$ \\
\hline Lag População (em log) & $\begin{array}{c}0.508 * * * \\
(0.0191)\end{array}$ & $\begin{array}{c}0.482 * * * \\
(0.0191)\end{array}$ & $\begin{array}{c}0.498 * * * \\
(0.0185)\end{array}$ & $\begin{array}{c}3,084 * * * \\
(341.2)\end{array}$ & $\begin{array}{c}3,021 * * * \\
(342.6)\end{array}$ & $\begin{array}{c}2,993 * * * \\
(338.3)\end{array}$ \\
\hline População (em log) & $\begin{array}{c}-0.766^{* * * *} \\
(0.0209)\end{array}$ & $\begin{array}{c}-0.702 * * * \\
(0.0242)\end{array}$ & $\begin{array}{c}-0.753^{* * *} * \\
(0.0204)\end{array}$ & $\begin{array}{c}-4,141^{* * * *} \\
(382.8)\end{array}$ & $\begin{array}{c}-3,977 * * * \\
(397.9)\end{array}$ & $\begin{array}{c}-3,908 * * * * \\
(407.0)\end{array}$ \\
\hline Trab. Formais com Superior Completo (por 100 mil habitantes) & $\begin{array}{c}3.16 \mathrm{e}-06 \\
(2.31 \mathrm{e}-06)\end{array}$ & $\begin{array}{c}3.31 \mathrm{e}-06 \\
(2.41 \mathrm{e}-06)\end{array}$ & $\begin{array}{c}3.32 \mathrm{e}-06 \\
(2.43 \mathrm{e}-06)\end{array}$ & $\begin{array}{l}0.0365^{*} \\
(0.0216)\end{array}$ & $\begin{array}{l}0.0359^{*} \\
(0.0216)\end{array}$ & $\begin{array}{c}0.0345 \\
(0.0217)\end{array}$ \\
\hline Lag Óbitos Evitáveis de Crianças (por 100 mil habitantes) & $\begin{array}{c}9.67 \mathrm{e}-06 \\
(4.45 \mathrm{e}-05)\end{array}$ & $\begin{array}{l}-1.81 \mathrm{e}-06 \\
(4.47 \mathrm{e}-05)\end{array}$ & $\begin{array}{c}3.80 \mathrm{e}-06 \\
(4.49 \mathrm{e}-05)\end{array}$ & $\begin{array}{l}-1.187 \\
(0.742)\end{array}$ & $\begin{array}{l}-1.208 \\
(0.741)\end{array}$ & $\begin{array}{c}-1.228^{*} \\
(0.740)\end{array}$ \\
\hline Receita de Transf. (ex-royalties) per capita (em log) & & $\begin{array}{c}0.0673 * * * \\
(0.0130)\end{array}$ & & & $\begin{array}{c}168.2 \\
(131.9)\end{array}$ & \\
\hline Receita Corrente (ex-royalties) per capita (em log) & & & $\begin{array}{c}0.0118^{* * * *} \\
(0.00414)\end{array}$ & & & $\begin{array}{c}236.9 \\
(156.0)\end{array}$ \\
\hline Constante & $\begin{array}{c}6.966 * * * \\
(0.253)\end{array}$ & $\begin{array}{c}6.202 * * * \\
(0.297)\end{array}$ & $\begin{array}{c}6.916^{* * * *} \\
(0.260)\end{array}$ & $\begin{array}{c}6.210^{* * * *} \\
(0.743)\end{array}$ & $\begin{array}{c}5.681^{* * *} \\
(0.845)\end{array}$ & $\begin{array}{c}5.450^{* * * *} \\
(0.986)\end{array}$ \\
\hline \# Observações & 36,342 & 35,325 & 35,345 & 3,177 & 3,177 & 3,177 \\
\hline Suporte Comum & NÃO & NÃO & NÃO & SIM & SIM & SIM \\
\hline R-Quadrado & 0.307 & 0.311 & 0.309 & 0.364 & 0.365 & 0.366 \\
\hline \# Municípios & 5,520 & 5,512 & 5,512 & 696 & 696 & 696 \\
\hline Dummy Ano & SIM & SIM & SIM & SIM & SIM & SIM \\
\hline
\end{tabular}

\section{ROYALTIES, GASTO PÚBLICO E DESENVOLVIMENTO}


Neste capítulo é feita uma breve discussão sobre um canal por meio do qual as transferências de royalties do petróleo poderiam afetar o desenvolvimento econômico dos municípios beneficiados - o orçamento público. Dadas as evidências que refutam a tese de MRN no país, a questão que emerge é por que esses recursos geram resultados decepcionantes sobre indicadores que medem o nível socio-econômico das localidades? Em síntese, a resposta está na falta de qualidade do gasto público e de regras rígidas para a gestão dessa receitas de recursos exauríveis.

Para desenvolver essa ideia, utiliza-se como inspiração a tese de Monteiro e Ferraz (2010), segundo a qual, a produção de petróleo afeta variáveis municipais somente através do orçamento público. Os autores embasam essa ideia tanto com evidências téoricas, quanto empíricas; primeiramente, eles apontam que $90 \%$ da produção é efetuada em plataformas de petróleo na costa brasileira e isso minimiza o impacto da atividade sobre as cidades litorâneas; em seguida, eles trazem evidências de que a produção de petróleo não afeta o número de empresas em diferentes setores da economia, o número de funcionários e a folha de pagamento do setor privado, mas encontram um efeito positivo sobre a massa salarial no setor público, fortalecendo a tese de canal orçamentário.

O método aplicado neste capítulo é análogo ao desenvolvido anteriormente - o uso do Duplamente Robusto em um painel de municípios observados - com o objetivo de analisar a relação entre royalties do petróleo e diferentes categorias de despesa do orçamento, controlando pelas receitas tributária e de transferências, população municipal e resultado orçamentário do período anterior. Novamente, é importante ressaltar que os resultados apresentados não podem ser interpretados como efeitos marginais, por isso são os sinais dos coeficientes e sua significância que assumem particular destaque.

A importância desse exercício se insere no contexto dos resultados apresentados no capítulo anterior, bem como dos trabalhos mencionados na revisão bibliográfica. Uma vez constatado que os royalties tiveram um forte aumento em termos reais na última década, que essas receitas não afetam o PIB local neste trabalho e que os royalties apresentam impactos decepcionantes sobre indicadores socio-econômicos no Brasil segundo a literatura, caso as despesas municipais dos tratados tenham apresentado um crescimento real no período, a hipótese de "missing money" de Caselli e Michaels (2013) pode ser parte da resposta à pergunta do começo do capítulo. Segundo os autores, a explicação para o problema pode estar relacionada à desvios de finalidade dos recursos públicos, como enriquecimento ilícito e compra de votos. Por outro lado, apesar dos avanços com o criação do Fundo Social, a 
ausência de regras mais restritivas para a gestão dessas receitas contribui decisivamente para o seu uso inapropriado.

Antes de prosseguir com a estimação proposta, é importante verificar se houve balanceamento dos controles utilizados. De acordo com a Tabela 7, não foi possível eliminar as diferenças nas médias entre tratados e não-tratados apenas das receitas de transferências; para as demais, a hipótese de igualdade entre as médias não é rejeitada. Dessa modo, parte-se para a apresentação dos resultados obtidos na Tabela 13. Note que, para cada categoria de despesa, foram estimados o ATT sob três especificações, mediante inclusão de dummy de ano e restrição da amostra para o suporte comum, partindo do modelo mais parcimonioso (controlado apenas por população) até o mais abrangente (com inclusão das principais categorias de receitas municipais - a tributária e de transferências - e do resultado orçamentário do período anterior). Observa-se que, com exceção das despesas com pessoal, todas as demais categorias têm uma relação positiva e significante com o recebimento de royalties no período analisado. Logo, assumindo que o orçamento público seja o principal canal pelo qual os efeitos dos royalties se manifestariam, o incremento substancial no volume de recursos dos beneficiados contribuiu para a evolução de suas despesas, sem progressão no desenvolvimento econômico local, seja na ótica do crescimento, elaborada neste trabalho, seja na ótica social, explorada na literatura para o Brasil (ver Capítulo 2) e que foge ao escopo desta dissertação. 


\begin{tabular}{|c|c|c|c|}
\hline 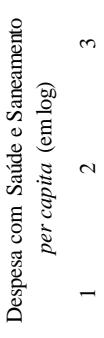 & 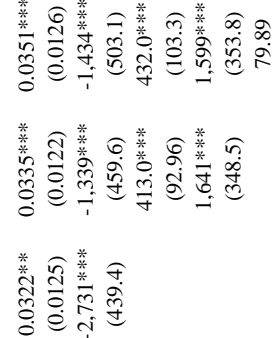 & 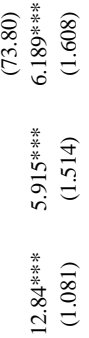 & 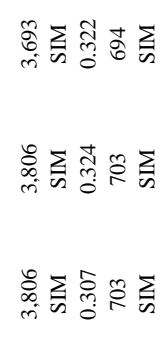 \\
\hline 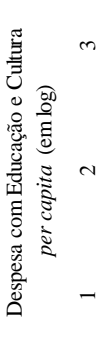 & 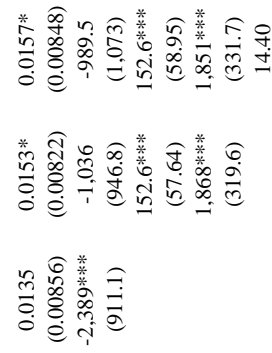 & 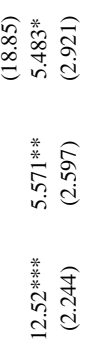 & 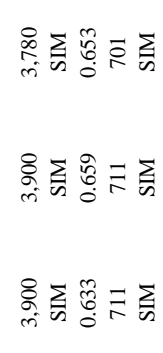 \\
\hline 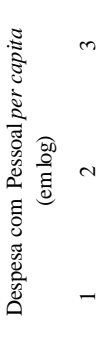 & 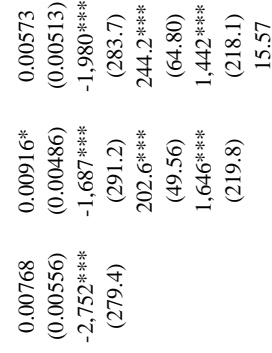 & 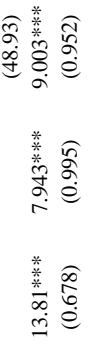 & 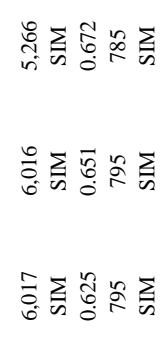 \\
\hline 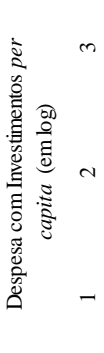 & 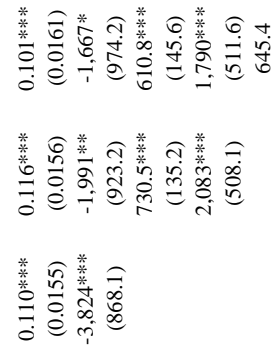 & 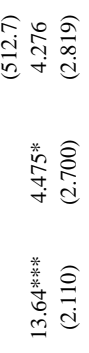 & 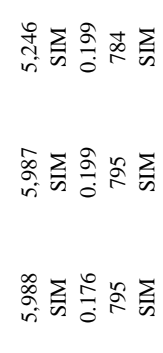 \\
\hline م & 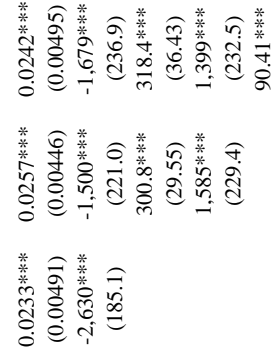 & 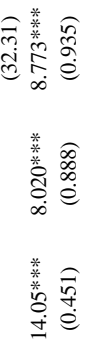 & 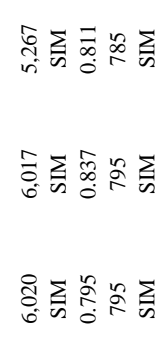 \\
\hline 甚 & 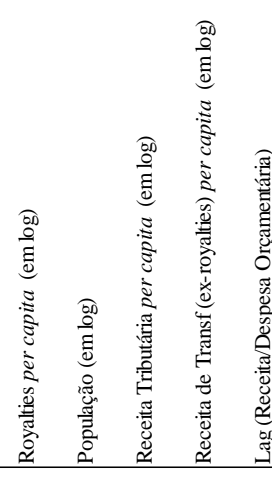 & 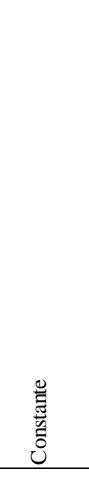 & 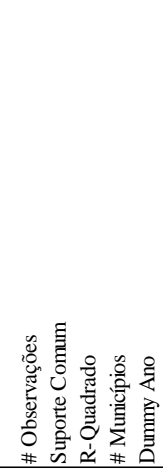 \\
\hline
\end{tabular}




\section{CONSIDERAÇÕES FINAIS}

No Brasil, em meio ao cenário de recuperação de crise econômica e política, e de estabilização dos preços internacionais do petróleo (em patamar 50\% inferior ao do começo da década), as cidades beneficiadas pelos chamados royalties do petróleo se deparam com o desafio de manter as funcionalidades públicas em meio à redução de suas receitas. Esse contexto atual adverso ilustra quão importante é a questão do melhor aproveitamento do capital proveniente desses recursos não-renováveis.

A partir de uma metodologia que permite uma melhor comparabilidade entre os grupos de tratamento e de controle, o método Duplamente Robusto, esta dissertação buscou investigar qual o efeito do recebimento das rendas do petróleo sobre o desenvolvimento dos municípios, medido pela taxa de crescimento do PIB per capita. A principal vantagem desse método é a geração de estimadores consistentes quando o propensity score ou o modelo de regressão é especificado corretamente, daí a dupla robustez.

Em contraposição aos trabalhos anteriores que validam a Maldição dos Recursos Naturais no setor petrolífero nacional, os resultados apontam que os royalties não têm efeito sobre o crescimento do produto municipal. No entanto, considerando que o orçamento seja o principal canal pelo qual as rendas petrolíferas afetariam as realidades locais, é preocupante a associação positiva entre tais receitas e as despesas gerais dos municípios sem uma progressão no desenvolvimento econômico local.

A principal limitação deste trabalho empírico com base em dados municipais é a indisponibilidade de dados, ora em razão de as séries não serem muito longas, ora por simplesmente não existirem para esse nível de desagregação. Apesar da notável melhora na qualidade e quantidade de indicadores desagregados disponíveis no país nos últimos anos, ainda há carência de dados confiáveis e de horizonte temporal razoável.

Finalmente, esta dissertação pode ser estendida em diversas direções, seja através de uma melhor especificação dos modelos utilizados, seja combinando o propensity score com outros métodos a exemplo do diff-in-diff ou ainda explorando diferentes canais por meio dos quais os royalties afetam o desenvolvimento. Além disso, é possível utilizar essa metodologia para aperfeiçoar os estudos existentes acerca dos efeitos das rendas petroleiras sobre indicadores sociais e fiscais de municípios. 


\section{REFERÊNCIAS BIBLIOGRÁFICAS}

ALEXEEV, M.; CONRAD, R. The Elusive Curse of Oil. Review of Economics and Statistics, 91, no. 3, 2009, 586-98.

ANSHASY, Amany A. Oil windfall shocks, government spending, and the resource curse. Journal of Applied Business and Economics, v. 12, n. 4, p. 44-63, 2011.

ATKINSON, Giles; HAMILTON, Kirk. Savings, growth and the resource curse hypothesis. World Development, v. 31, n. 11, p. 1793-1807, 2003.

BANG, H.; ROBINS, J. M. Doubly robust estimation in missing data and causal inference models. Biometrics, 61, 2005, 962-972.

BARRO, R.J., SALA-I-MARTIN, X.X., 1995. Economic Growth. McGraw-Hill, New York, NY.

BIONDI, R. L.; VASCONCELLOS, L. AND MENEZES-FILHO, N. Evaluating the impact of the Brazilian Public School Math Olympics on the quality of education. Economía, 12, 2012, 143-175.

BRAVO-ORTEGA, C.; GREGORIO, J. D. The Relative richness of the poor? Natural resources, human capital and economic growth. Washington, D.C.: The World Bank, 2005 (Policy Research Working Paper, n. 3484).

BROLLO, F.; NANNICINI, T. Tying Your Enemy's Hands in Close Races: The Politics of Federal Transfers in Brazil. American Political Science Review, 106(4), 2012, pp. 742-761.

CANUTO, O.; CAVALLARI M. Natural Capital and the Resource Curse. The World Bank, No 83, May, 2012.

CARNICELLI, L.; POSTALI, F. Rendas do Petróleo e Tributos Locais: uma análise de propensity score. In: Anais do XL Encontro Nacional de Economia (ANPEC). Porto de Galinhas-PE, 2012.

CARNICELLI, L.; POSTALI, F. Royalties do petróleo e emprego público nos municípios Brasileiros. Estudos Econômicos (São Paulo), 44(3), 469-495, 2014.

CASELLI, F.; MICHAELS, G. Do Oil Windfalls Improve Living Standards? Evidence from Brazil. American Economic Journal: Applied Economics, American Economic Association, vol. 5(1), pp. 208-38, January, 2013.

COLLIER, P. The Bottom Billion - Why the Poorest Countries are Failing and What Can Be Done About It. Oxford University Press, New York, 2007.

COSTA NOVA, L. Análise do impacto social de receitas provenientes de royalties do petróleo em municípios do estado da Bahia. Dissertação de Mestrado, Universidade de Brasília, 2005.

DAVIS, Jeffrey; OSSOWSKI, Rolando; DANIEL, James; BARNETT, Steven. Stabilization 
and savings funds for non-renewable resources: experience and fiscal policy implications. Washington D.C.: International Monetary Fund, 2001. (Occasional Paper, n.205).

DEHEJIA, R.H.; WAHBA, S. Causal effects in nonexperimental studies: reevaluating the evaluation of training programs. Journal of the American Statistical Association 94(448), 1999, 1053-1062.

DEHEJIA, R.H.; WAHBA, S. Propensity Score-Matching Methods for Nonexperimental Causal Studies. Review of Economics and Statistics 84 (1), 2002, pp. 151-161.

FEDERAÇÃO DAS INDÚSTRIAS DO ESTADO DO RIO DE JANEIRO (FIRJAN). Nota Metodológica Índice FIRJAN de Desenvolvimento Municipal (IFDM) 2015. Disponível em: <http://www.firjan.com.br/data/files/B7/43/4A/72/CE2615101BF66415F8A809C2/Anexo \%20Metodol\%C3\%B3gico\%20IFDM.pdf>. Acesso em: 27 abr. 2017.

FERNANDES, J. L. T. Maldição dos recursos naturais e produtividade do gasto público nos municípios brasileiros. 2016. 140 f., il. Tese (Doutorado em Ciências Contábeis) - Programa Multi-institucional e Inter-Regional de Pós-Graduação em Ciências Contábeis, Universidade de Brasília, Universidade Federal da Paraíba, Universidade Federal do Rio Grande do Norte, Brasília, 2016.

GALIANI, S; GERTLER, P; SCHARGRODSKY, E. Water for Life: The Impact of the Privatization of Water Services on Child Mortality. Journal of Political Economy, Vol. 113, No. 1, 2005, pp. 83-120.

HARTWICK, J.M. Intergenerational Equity and the Investing of Rents from Exhaustible Resources. American Economic Review 67, n 5, dez. 1977, 972-974.

IMBENS, Guido W. \& WOOLDRIDGE, Jeffrey M. Recent Developments in the Econometrics of Program Evaluation. Journal of Economic Literature, American Economic Association, vol. 47(1), mar/2009, pp. 5-86.

INSTITUTO BRASILEIRO DE GEOGRAFIA E ESTATÍSTICA (IBGE). Produto Interno Bruto dos Municípios. Série Relatórios Metodológicos, vol. 29, Rio de Janeiro, 2004. Disponível em: 〈http://biblioteca.ibge.gov.br/visualizacao/livros/liv41219.pdf>. Acesso em: 27 abr. 2017.

JAMES, Alex; AADLAND, David. The Curse of Natural Resources: an empirical investigation of U.S. counties. Resource and Energy Economics, v. 33, n.2, p. 440-453, 2011.

LANE, P. R.; TORNELL, A. Power, growth and the voracity effect. Journal of Economic Growth, vol. 1, 1996, pp. 213-41.

MEHLUM, H.; MOENE, K.; TORVIK, R. Institutions and the Resource Curse. Economic Journal, 116(508), 2006, 1-20.

MONTEIRO, J.; FERRAZ, C. Does Oil Make Leaders Unaccountable? Evidence from Brazil's Offshore Oil Boom. Pontificia Universidade Catolica do Rio de Janeiro, 2012. 
PAPYRAKIS, Elissaios. GERLAGH, Reyer. Resource abundance and economic growth in the United States. European Economic Review, v. 51, n. 4, p. 1011-1039, 2007.

POSTALI, F. Petroleum royalties and regional development in Brazil: the economic growth of recipient towns. Resources Policy, vol. 34, 2009, 205-213.

POSTALI, F. Tax effort and oil royalties in the Brazilian municipalities. EconomiA, vol. 16, issue 3, September-December, 2015, pp. 395-405.

POSTALI, F.; ROCHA, F. Resource windfalls, fiscal effort and public spending: evidence from Brazilian municipalities. In: Anais do XXXVII Encontro Nacional de Economia (ANPEC). Foz do Iguaçu-PR, 2009.

POSTALI, F.; NISHIJIMA, M. Distribuição das rendas do petróleo e indicadores de desenvolvimento municipal no Brasil nos anos 2000. Estudos Econômicos, 41(2), 2011, 463 485 .

POSTALI, F.; NISHIJIMA, M. Oil windfalls in Brazil and their long-run social impacts. Resources Policy, 38(1), 2013, 94-108.

RAJ, D. Development Economics, Princeton, NJ, Princeton University Press, 1998.

ROBINSON, J. A.; TORVIK, R.; VERDIER, T. Political foundations of the resource curse. Journal of Development Economics 79, 2006, 447-468.

ROSENBAUM, P. R.; RUBIN, D. B. The Central Role of the Propensity Score in Observational Studies for Causal Effects. Biometrika 70, 1983, 41-55.

SACHS, J.; WARNER, A. Natural Resource Abundance and Economic Growth, NBER Working Paper Series, No. 5398, 1995.

SACHS, J.; WARNER, A. The big push, natural resource booms and growth. Journal of Development Economics, vol. 59, 1999, pp. 43-76.

SACHS, J.; WARNER, A. The curse of natural resources. European Economic Review, vol. 45, 2001, pp. 827-838.

TORNELL, A. AND LANE, P.R. The voracity effect. American Economic Review, vol. 89, 1999, pp. 22-46.

WOOLDRIDGE, J.M. Econometric Analysis of Cross Section and Panel Data. Cambridge and London: MIT Press, 2002. 


\section{APÊEDICE}

Tabela 14 - Estimação com Variáveis Defasadas e Contemporâneas Selecionadas II

\begin{tabular}{|c|c|c|c|c|c|c|}
\hline \multirow{2}{*}{ Taxa de Crescimento do PIB per capita (anual) } & \multicolumn{3}{|c|}{ Efeitos Fixos } & \multicolumn{3}{|c|}{ ATT } \\
\hline & 1 & 2 & 3 & 1 & 2 & 3 \\
\hline Royalties per capita (em log) & $\begin{array}{c}0.0218 * * * \\
(0.00787)\end{array}$ & $\begin{array}{l}0.0198 * * \\
(0.00798)\end{array}$ & $\begin{array}{c}0.0208 * * * \\
(0.00805)\end{array}$ & $\begin{array}{c}0.0207 \\
(0.0140)\end{array}$ & $\begin{array}{c}0.0213 \\
(0.0139)\end{array}$ & $\begin{array}{c}0.0217 \\
(0.0139)\end{array}$ \\
\hline Lag PIB per capita (em log) & $\begin{array}{c}-0.441^{* * * *} \\
(0.0113)\end{array}$ & $\begin{array}{c}-0.453 * * * \\
(0.0107)\end{array}$ & $\begin{array}{c}-0.447 * * * * \\
(0.0106)\end{array}$ & $\begin{array}{c}-1,842 * * * \\
(144.0)\end{array}$ & $\begin{array}{c}-1,869 * * * \\
(146.4)\end{array}$ & $\begin{array}{c}-1,870 * * * \\
(146.5)\end{array}$ \\
\hline Lag População (em log) & $\begin{array}{c}0.500 * * * \\
(0.0189)\end{array}$ & $\begin{array}{c}0.472 * * * \\
(0.0190)\end{array}$ & $\begin{array}{c}0.487 * * * \\
(0.0185)\end{array}$ & $\begin{array}{c}2,466 * * * \\
(371.2)\end{array}$ & $\begin{array}{c}2,366^{* * * * *} \\
(366.9)\end{array}$ & $\begin{array}{c}2,361 * * * \\
(367.7)\end{array}$ \\
\hline População (em log) & $\begin{array}{c}-0.741^{* * * *} \\
(0.0224)\end{array}$ & $\begin{array}{c}-0.670^{* * * *} \\
(0.0258)\end{array}$ & $\begin{array}{c}-0.724 * * * * \\
(0.0225)\end{array}$ & $\begin{array}{c}-3,754 * * * \\
(391.5)\end{array}$ & $\begin{array}{c}-3,488^{* * *} \\
(388.9)\end{array}$ & $\begin{array}{c}-3,451 \text { **** } \\
(384.9)\end{array}$ \\
\hline IFDM Educação (relativo à média nacional) & $\begin{array}{l}-0.00989 \\
(0.00919)\end{array}$ & $\begin{array}{c}-0.0123 \\
(0.00923)\end{array}$ & $\begin{array}{c}-0.0119 \\
(0.00925)\end{array}$ & $\begin{array}{l}-62.42 \\
(178.7)\end{array}$ & $\begin{array}{l}-68.64 \\
(179.1)\end{array}$ & $\begin{array}{l}-58.80 \\
(178.9)\end{array}$ \\
\hline Lag IFDM Saúde (relativo à média nacional) & $\begin{array}{c}0.00531 \\
(0.00772)\end{array}$ & $\begin{array}{c}0.00511 \\
(0.00784)\end{array}$ & $\begin{array}{c}0.00668 \\
(0.00783)\end{array}$ & $\begin{array}{l}-70.55 \\
(129.0)\end{array}$ & $\begin{array}{l}-75.59 \\
(129.0)\end{array}$ & $\begin{array}{l}-81.74 \\
(128.9)\end{array}$ \\
\hline Receita de Transf. (ex-royalties) per capita (em log) & & $\begin{array}{c}0.0762 * * * \\
(0.0134)\end{array}$ & & & $\begin{array}{l}290.9^{* * *} \\
(144.6)\end{array}$ & \\
\hline Receita Corrente (ex-royalties) per capita (em log) & & & $\begin{array}{c}0.0156^{* * * *} \\
(0.00508)\end{array}$ & & & $\begin{array}{c}339.2 * * \\
(134.4)\end{array}$ \\
\hline Constante & $\begin{array}{c}6.591 * * * \\
(0.221)\end{array}$ & $\begin{array}{c}5.707 * * * \\
(0.277)\end{array}$ & $\begin{array}{c}6.493 * * * \\
(0.233)\end{array}$ & $\begin{array}{c}7.388^{* * *} \\
(0.914)\end{array}$ & $\begin{array}{c}6.506^{* * * *} \\
(1.055)\end{array}$ & $\begin{array}{c}6.328 * * * \\
(1.025)\end{array}$ \\
\hline \# Observações & 44,516 & 43,301 & 43,323 & 3,351 & 3,351 & 3,351 \\
\hline Suporte Comum & NÃO & NÃO & NÃO & SIM & SIM & SIM \\
\hline R-Quadrado & 0.270 & 0.275 & 0.272 & 0.319 & 0.320 & 0.321 \\
\hline \# Municípios & 5,565 & 5,560 & 5,560 & 714 & 714 & 714 \\
\hline Dummy Ano & SIM & SIM & SIM & SIM & SIM & SIM \\
\hline
\end{tabular}

Fonte: Elaboração própria. Dados em valores reais calculados a partir do IPCA 2016. Desvio padrão robusto entre parêntesis. (***) Significativo a $1 \%,(* *)$ Significativo a $5 \%,(*)$ Significativo a $10 \%$. 